\title{
Numerical Investigation of Load-Carrying Capacity of GFRP-Reinforced Rectangular Concrete Members Using CDP Model in ABAQUS
}

\author{
Ali Raza, Qaiser uz Zaman Khan, and Afaq Ahmad $\mathbb{D}$ \\ Department of Civil Engineering, University of Engineering and Technology, Taxila 47080, Pakistan \\ Correspondence should be addressed to Afaq Ahmad; afaq.ahmad@uettaxila.edu.pk
}

Received 28 September 2018; Revised 29 January 2019; Accepted 10 February 2019; Published 3 March 2019

Academic Editor: Qingliang Yu

Copyright ( 2019 Ali Raza et al. This is an open access article distributed under the Creative Commons Attribution License, which permits unrestricted use, distribution, and reproduction in any medium, provided the original work is properly cited.

\begin{abstract}
The present work demonstrates the nonlinear finite element analysis (NLFEA) of 13 concentrically and eccentrically loaded short rectangular concrete column specimens reinforced with GFRP and conventional steel bars. GFRP bars are lightweight having the high tensile strength and high corrosion resistance. An NLFEA model for the rectangular concrete specimens was developed using the commercial software ABAQUS Standard and calibrated for different materials and geometric parameters based on the previous experimental test results of the studied specimen. The behavior of reinforced concrete was modelled using the concrete damaged plasticity (CDP) model, the behavior of steel bars was simulated as a bilinear elastoplastic material, and the GFRP bars were considered as a linear elastic material. After the calibration of CDP parameters, the control sample was used for the further numerical parametric analysis to investigate the effect of critical parameters, i.e., the area of concrete $\left(A_{c}\right)$, the compressive strength of concrete $\left(f_{\mathrm{c}}^{\prime}\right)$, and the ratio of longitudinal reinforcement $\left(\rho_{1}\right)$ and transverse reinforcement $\left(\rho_{\mathrm{t}}\right)$ on the load-carrying capacity of columns. The results show that the selected NLFEA model can simulate the behavior of columns accurately and there was good agreement of numerical results obtained from ABAQUS Standard with the experimental results.
\end{abstract}

\section{Introduction}

Glass fiber-reinforced polymer (GFRP) is a lightweight, corrosion resistant, nonmagnetic and electrically insulating material with a very high tensile strength and low thermal conductivity. GFRP bars are used as a viable replacement of steel bars in reinforced concrete structures. Due to nonmagnetic and nonconductive properties of the GFRP material, it can be preferred to use near sensitive instruments in laboratories and hospitals [1-4]. Also, the smaller concrete cover is used for GFRP-reinforced members due to the corrosion-resistant property of GFRP bars. In the wastewater and chemical treatment plants, marine structures, and the structures exposed to deicing salts, the corrosion of conventional steel causes the reduction of the serviceability of structures. Due to this problem, the steel-reinforced concrete (RC) structures in such aggressive environments have about 50 years of life only. The replacement of steel with
FRP composites such as GFRP bars could be useful in saving the tremendous repair costs for long-term serviceability and durability of structures [5]. Throughout the life of RC structures, GFRP bars have been found to be economical. Fiber-reinforced polymers (FRP) bars having a density of less than one-quarter of that of steel bars with higher tensile strength and corrosion resistance in chemical environments offer a number of advantages over steel $[6,7]$. Furthermore, due to high strength, high corrosion resistance, and less concrete cover, GFRP bars have high utilization for the retrofitting purpose of old or damage-reinforced concrete building [8].

Extensive experimental work has been done as compared to the numerical work by research groups on the behavior of GFRP RC compression and flexural members. Nguyen et al. [9] studied lateral-torsional buckling (LTB) of fiber-reinforced polymer (FRP) I-beams by using nonlinear finite element analysis and concluded that due to change in 
load height and end warping fixity, the beam with FRP has larger effect on buckling strength as compared to the beam with steel elastic constants. Yang et al. [10] examined the damage behavior of GFRP RC beams by performing the experimental and FEA and reported that the developed FEA model is accurate enough to predict the damage behavior of GFRP RC beams. Amiri et al. [11] presented a FE model of reinforced geopolymer concrete flexural members using commercial software ABAQUS and found a deviation in experimental and numerical results for deflections, but the crack pattern showed good agreement. Najafgholipour et al. [12] conducted the FEA of reinforced concrete exterior and interior beam-column joints by using the CDP model in ABAQUS and studied deformations, joint shear capacity, and cracks patterns with the conclusion that FEA results are in good agreement with the experimental results. Prachasaree et al. [5] studied the behavior of GFRP RC columns with different types of stirrups and concluded that the effect of longitudinal GFRP reinforcement on the strength of a column is slight, but transverse reinforcement significantly affects the confining pressure by increasing the concrete strength and inelastic deformation. Alsayed et al. [13] performed the tests on $450 \times 250 \times 1200 \mathrm{~mm}$ columns under concentric loading and concluded that, by using same longitudinal reinforcement ratio of steel and GFRP bars, the capacity of GFRP-reinforced columns is decreased by $13 \%$. Nunes et al. [14] conducted the experimental and numerical investigations on GFRP pultruded columns which were subjected to eccentric loadings and concluded that when the load is applied within the kern boundary, the loadcarrying capacity of the column is decreased up to $40 \%$. Furthermore, a good agreement was achieved between experimental and numerical results. Turvey and Zhang [15] also conducted an experimental and numerical study to investigate the failure mechanism of postbuckled GFRPreinforced short concrete columns. The numerical study was conducted by using both generalized beam theory (GBT) and ABAQUS.

From the literature review, it has been observed that the numerical behavior of the GFRP-reinforced compression members using FEA software ABAQUS is less defined and no numerical parametric study was conducted. Therefore, to accurately simulate and analyze the numerical behavior of GFRP reinforcement in columns and to provide new design codes for GFRP reinforcement, an experimental and numerical parametric study is needed by examining the critical parameters that influence the axial capacity of RC columns. The primary objective of the present research is to propose a NLFEA model in ABAQUS which accurately simulates the behavior of reinforced concrete and to validate it against the previous experimental test results of load-deflection curves of 13 column specimens. After the validation of the NLFEA model, this calibrated numerical model was used to establish the load-deflection curves of columns compared with previous experimental results from Elchalakani and Ma [16], and then a numerical parametric study of steel and GFRP control specimens was done. The crack patterns of concrete in RC columns were also studied. Finally, the experimental and FEA results of concentrically loaded steel and GFRP RC columns were compared with theoretical results. The significance of the present work is that the proposed FEA ABAQUS model can be utilized for the further analysis of different parameters of columns.

\section{Finite Element Modelling}

2.1. General Methodology. Numerical simulations of GFRPreinforced concrete columns were done by using commercial software ABAQUS Standard 6.12. During the modelling of specimens, the concrete material models, boundary conditions, and different geometric and material parameters were discussed in detail. The concrete material was modelled as a homogeneous $3 \mathrm{D}$ solid section. Drucker-Prager plasticity model was used for the numerical simulations of FRP confined concrete [17-19]. Generally, the numerical model should be rich enough to be capable of capturing the critical and essential phenomena but should not be complex enough to increase the analysis time of the computer. After simulating the geometry of the control model, it was calibrated for dilation angle, stress ratio, shape factor, plastic potential eccentricity, and viscosity parameter of the concrete damaged plasticity (CDP) model, different element types, and mesh sizes to achieve better results as compared with previous experimental results.

\subsection{Model Geometry, Boundary Conditions, and Loading.} All the steel and GFRP RC columns were fixed at the bottom, and the top end was kept free in all directions with the applied axial loading. Embedded region constraint available in ABAQUS Standard was used to define the bonding of reinforcing bars, i.e., steel and GFRP bars, with concrete which limits the nodes of reinforcing bars elements to the compatible degrees of freedom (DOF) of the host region elements (concrete), as shown in Figure 1(c). To determine the axial load-deflection history of reinforced concrete columns up to failure, a static monotonic loading was applied on the top by the displacement control technique. An induced displacement of $20 \mathrm{~mm}$ was applied on the top center of concentric columns and at a distance equal to required eccentricity from the center of specimens along the weaker axis of eccentric columns. Steel plates of $50 \mathrm{~mm}$ thickness were attached to the top and bottom of the columns using "tie constraint" for the application of boundary conditions and equal distribution of applied loads. These plates were considered as rigid elements with Young's modulus of $210 \mathrm{GPa}$ and density of $7.85 \cdot 10^{-9} \mathrm{ton} / \mathrm{mm}^{3}$. The geometry and the modelling details of the finite element models of steel-reinforced columns are shown in Figure 1.

The different concrete material properties and loading increments and sizes in Step Module of ABAQUS Standard are given in Table 1 . The modulus of elasticity $\left(E_{\mathrm{c}}\right)$ of concrete was calculated using the ACI code given by

$$
E_{\mathrm{c}}=4700 \sqrt{f_{\mathrm{c}}^{\prime}}
$$




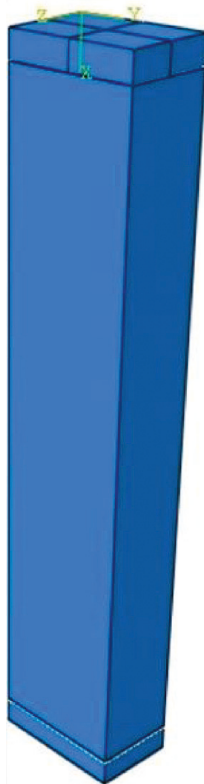

(a)

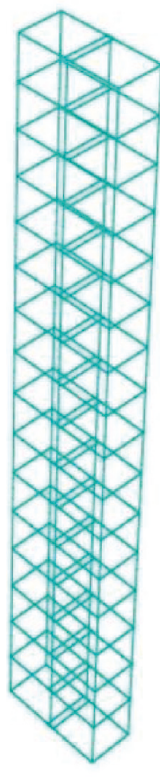

(b)

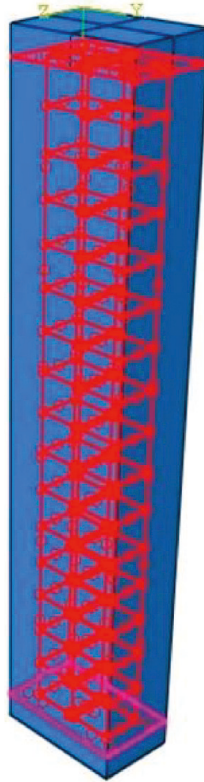

(c)

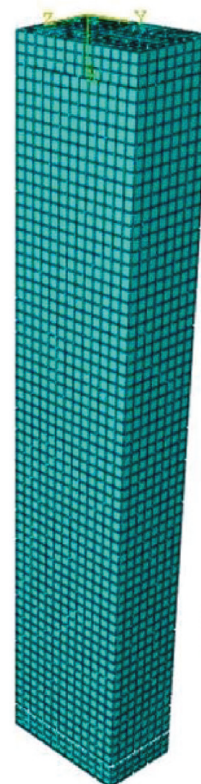

(d)

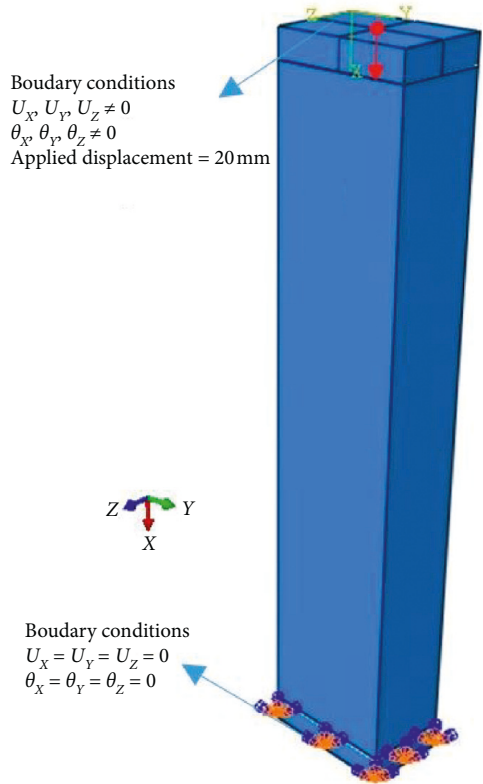

(e)

Figure 1: A typical steel-reinforced column's (a) geometry, (b) steel mesh, (c) embedded region constraints, (d) finite element meshing, and (e) boundary conditions.

TABLE 1: Different properties of concrete and loading increments.

\begin{tabular}{lc}
\hline Parameter & Value \\
\hline Density of concrete $\left(\right.$ ton $\left./ \mathrm{mm}^{3}\right)$ & $2.4 \times 10^{-9}$ \\
Poisson's ratio, $v$ & 0.2 \\
Young's modulus, $E_{\mathrm{c}}\left(\mathrm{N} / \mathrm{mm}^{2}\right)$ & 26587 \\
Concrete cover for steel specimens $(\mathrm{mm})$ & 40 \\
Concrete cover for GFRP specimens $(\mathrm{mm})$ & 20 \\
Initial and maximum increment size of the loading & 0.01 \\
Minimum increment size & $10^{-10}$ \\
\hline
\end{tabular}

The master and slave surface concept was used to define the interaction between concrete columns and steel plates. The bottom surface of the top steel plate and the bottom surface of the column were taken as master surfaces, and the top surface of the column and the top surface of the bottom steel plate were considered as slave surfaces. In other words, the load transferring surfaces were taken as master surfaces. The smaller concrete clear cover was used for GFRP RC specimens due to the corrosion resistant property of GFRP bars according to Elchalakani et al. The geometry and modelling details of finite element models of GFRP RC columns were shown in Figure 2.

A total of 13 full-scale rectangular RC column specimens were modelled in ABAQUS under different loading conditions, from which 6 specimens were reinforced longitudinally and transversely with steel bars and remaining 7 specimens were reinforced with GFRP bars. Three loading eccentricities $(25 \mathrm{~mm}, 35 \mathrm{~mm}$, and $45 \mathrm{~mm})$ and three ligature spacings ( $75 \mathrm{~mm}, 150 \mathrm{~mm}$ and $250 \mathrm{~mm}$ ) were used to study their effect on the load-deflection behavior of compression members.

The used ultimate compressive strength of concrete was $32 \mathrm{MPa}$. The geometric and material characteristics of all specimens are shown in Table 2.
2.3. Concrete Damaged Plasticity (CDP) Model. In ABAQUS, there are three constitutive models for defining the inelastic behavior of concrete including concrete smeared cracking model (CSCM), concrete damaged plasticity (CDP) model, and brittle cracking concrete (BCC) model. The CDP model deals with plastic behavior, compressive behavior, tensile behavior, confinement, and damage mechanism of concrete and has the potential to converge the results to accuracy as compared with other models. In comparison with steel, concrete exhibits nonlinearity from the start when subjected to tension or the compression test.

The CDP model defines two failure mechanisms of concrete which are compressive crushing and tensile cracking. The CDP model is commonly accepted for the modelling of the nonlinear behavior of reinforced concrete [20-22]. Thus, in the current study, the behavior of the concrete material was defined by using the CDP model given by Liu and Chen [23], as shown in Figure 3 which describes the relationship between inelastic strain, plastic strain, and compression stress and strain of concrete. The damage parameter $d_{c}$, plastic strain $\mathcal{E}^{\mathrm{pl}}$, and inelastic strain $\mathcal{E}^{\text {in }}$ are determined using [23]. The CDP model in ABAQUS consists of plastic behavior, compressive behavior, and tensile behavior of concrete.

2.3.1. Plastic Behavior of Concrete. The parameters required to define the plasticity model of concrete are dilation angle $(\psi)$, the plastic potential eccentricity of concrete $(\varepsilon)$, the ratio of compressive stress in the biaxial state to the compressive stress in the uniaxial state $\left(\sigma_{\mathrm{b} 0} / \sigma_{\mathrm{c} 0}\right)$, the shape factor of the yielding surface in the deviatoric plane $\left(K_{c}\right)$, and viscosity parameter. The values of all these parameters were 


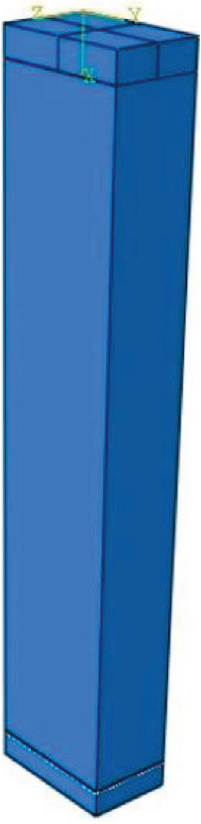

(a)

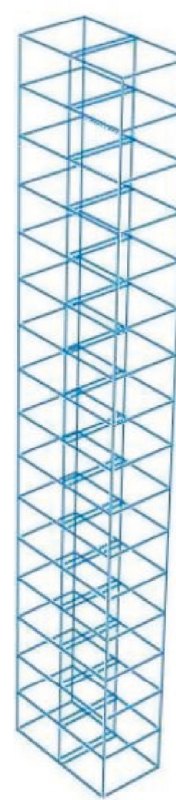

(b)

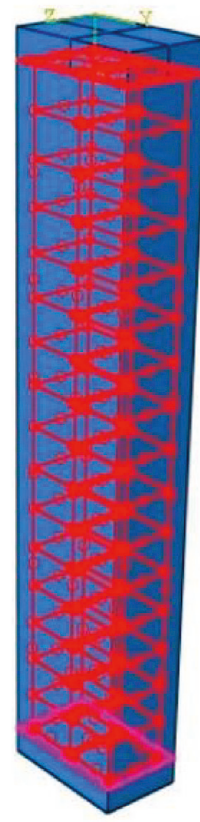

(c)

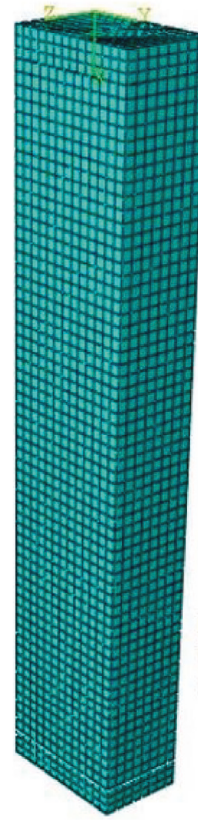

(d)

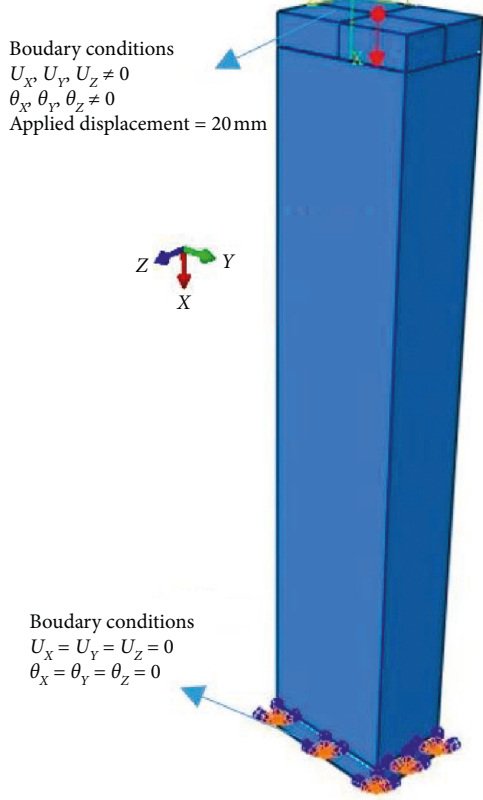

(e)

FIgURe 2: A typical GFRP-reinforced column's (a) geometry, (b) GFRP mesh, (c) embedded region constraints, (d) finite element meshing, and (e) boundary conditions.

TABLE 2: Geometric and material characteristics of column specimens.

\begin{tabular}{|c|c|c|c|c|c|c|c|c|}
\hline \multirow{2}{*}{$\begin{array}{l}\text { Sample } \\
\text { label }\end{array}$} & \multirow{2}{*}{$\begin{array}{l}\text { Reinforcement } \\
\text { type }\end{array}$} & \multirow{2}{*}{$\begin{array}{c}\text { Compressive } \\
\text { strength of } \\
\text { concrete }(\mathrm{MPa})\end{array}$} & \multicolumn{2}{|c|}{$\begin{array}{l}\text { Main } \\
\text { reinforcement }\end{array}$} & \multirow{2}{*}{$\begin{array}{l}\text { Concrete cover } \\
\quad(\mathrm{mm})\end{array}$} & \multicolumn{2}{|c|}{$\begin{array}{c}\text { Transverse } \\
\text { reinforcement }\end{array}$} & \multirow{2}{*}{$\begin{array}{l}\text { Test eccentricity } \\
(\mathrm{mm})\end{array}$} \\
\hline & & & Bars & $\begin{array}{l}\text { Reinforcement } \\
\text { ratio }(\%)\end{array}$ & & $\begin{array}{l}\text { Diameter of } \\
\text { bars }(\mathrm{mm})\end{array}$ & $\begin{array}{l}\text { Spacing } \\
(\mathrm{mm})\end{array}$ & \\
\hline $\begin{array}{l}\text { S45-150 } \\
\text { S25-150 } \\
\text { SC-150 } \\
\end{array}$ & Steel & 32 & $6-\phi 12 \mathrm{~mm}$ & 1.63 & 40 & 6 & 150 & $\begin{array}{c}45 \\
25 \\
0\end{array}$ \\
\hline $\begin{array}{l}\text { S35-75 } \\
\text { S25-75 } \\
\text { SC-75 } \\
\end{array}$ & Steel & 32 & 6- $\phi 12 \mathrm{~mm}$ & 1.63 & 40 & 6 & 75 & $\begin{array}{c}35 \\
25 \\
0\end{array}$ \\
\hline $\begin{array}{l}\text { G45-150 } \\
\text { G25-150 } \\
\text { GC-150 } \\
\end{array}$ & GFRP & 32 & $6-\phi 12.7 \mathrm{~mm}$ & 1.83 & 20 & 6.35 & 150 & $\begin{array}{c}45 \\
25 \\
0\end{array}$ \\
\hline $\begin{array}{l}\text { G35-75 } \\
\text { G25-75 } \\
\text { GC-75 } \\
\end{array}$ & GFRP & 32 & $6-\phi 12.7 \mathrm{~mm}$ & 1.83 & 20 & 6.35 & 75 & $\begin{array}{c}35 \\
25 \\
0 \\
\end{array}$ \\
\hline GC-250 & GFRP & 32 & $6-\phi 12.7 \mathrm{~mm}$ & 1.83 & 20 & 6.35 & 250 & 0 \\
\hline
\end{tabular}

obtained from calibration. The CDP model recommended values of the yield shape surface, $K_{c}$, and eccentricity, $\varepsilon$, which are $2 / 3$ and 0.1 , respectively. The specified value of $\sigma_{\mathrm{b} 0} / \sigma_{\mathrm{c} 0}$, by ABAQUS user manual [24], is 1.16. Also to quantify this stress ratio, Papanikolaou and Kappos [25] proposed equation (2) based on a large statistical data:

$$
\frac{\sigma_{\mathrm{b} 0}}{\sigma_{\mathrm{c} 0}}=1.5\left(f_{\mathrm{c}}^{\prime}\right)^{-0.075} \text {. }
$$

2.3.2. Compressive Behavior of Concrete. To define the compressive behavior of concrete in the CDP model, it is essential to give inelastic strain $\varepsilon^{\text {in }}$ in further increased degree so that compression failure of concrete can be defined at increased strain and peak elastic stress of concrete is to be provided in the compression behavior. According to Eurocode 2, the compressive stress-strain diagram for concrete has been shown in Figure 4. The linear elastic behavior can be taken up to $0.4 f_{\mathrm{cm}}$ according to Kmiecik and Kamiński [26]. To determine the strain $\varepsilon_{\mathrm{c} 1}$ at the average compressive strength of concrete and ultimate strain $\varepsilon_{\mathrm{cul}}$, Majewski [27] proposed the approximate relationships based on the experimental results given by the following equation:

$$
\begin{aligned}
\varepsilon_{\mathrm{cl}} & =0.0014\left[2-e^{-0.024 f_{\mathrm{cm}}}-e^{-0.140 f_{\mathrm{cm}}}\right], \\
\varepsilon_{\mathrm{cu} 1} & =0.004-0.0011\left[1-e^{-0.0215 f_{\mathrm{cm}}}\right] .
\end{aligned}
$$




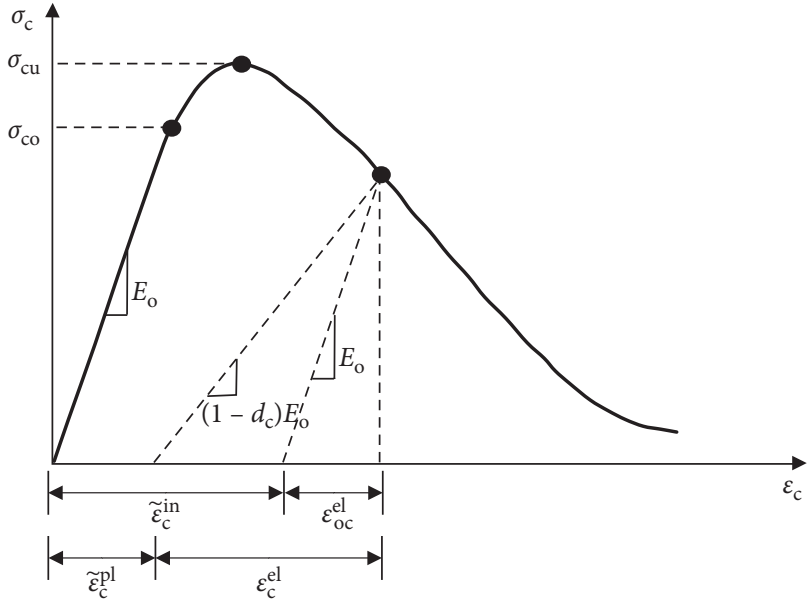

Figure 3: The plain concrete damaged plasticity model.

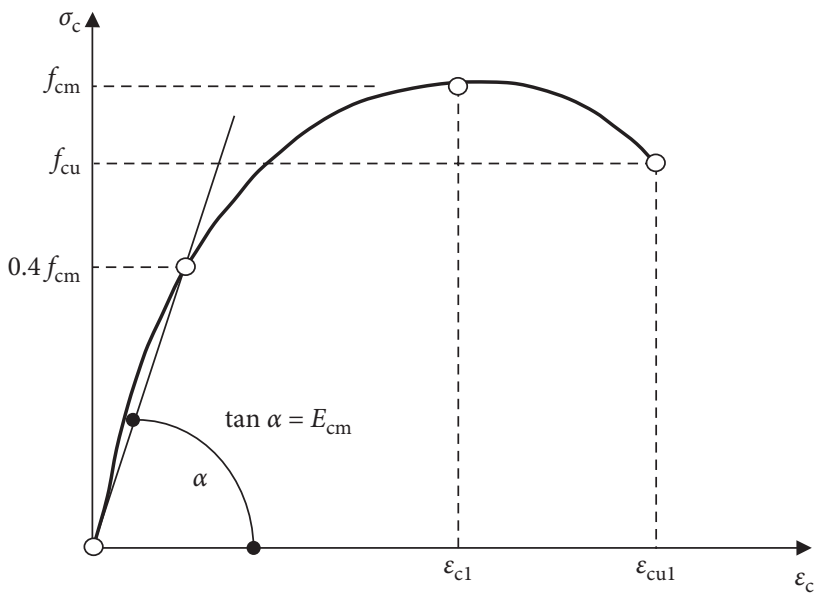

Figure 4: Stress-strain diagram for the analysis of structures (Eurocode 2).

Equation (4) given by Eurocode [28] for nonlinear behavior of structures was used in this research for modelling the stress-strain relationship of concrete:

$$
\sigma_{\mathrm{c}}=f_{\mathrm{cm}} \frac{k \eta-\eta^{2}}{1+(k-2) \eta}
$$

where

$$
\begin{aligned}
& k=1.05 E_{\mathrm{cm}} \frac{\varepsilon_{\mathrm{cl}}}{f_{\mathrm{cm}}}, \\
& \eta=\frac{\varepsilon_{\mathrm{c}}}{\varepsilon_{\mathrm{cl}}} .
\end{aligned}
$$

Desayi and Krishnan [29] also proposed the equation for the stress-strain relationship of nonlinear behavior of structures given by the following equation which can also be used:

$$
\sigma_{\mathrm{c}}=\frac{E_{0} \varepsilon}{1+\left(\varepsilon / \varepsilon_{\mathrm{co}}\right)^{2}},
$$

where $\varepsilon_{\mathrm{co}}$ is the compressive strain at peak loads and is equal to 0.002 according to Mander et al. [30].
2.3.3. Tensile Behavior of Concrete. For the simulation of tensile behavior of concrete, a stress-strain relationship at the postfailure condition is used for accounting tension stiffening, the interaction of reinforcement with concrete and strain softening. The tension stiffening model given by Nayal and Rasheed [31] is applicable for both fiberreinforced polymer (FRP) and steel-reinforced concrete. Wahalathantri et al. [32] modified the tension stiffening model of reinforced concrete given by Nayal and Rasheed [31] which was used for the present study and is shown in Figure 5. In this modified model, the only change was that the sudden drop of the tensile stress-strain curve at a critical strain $\varepsilon_{\mathrm{cr}}$ was from ultimate stress $\sigma_{\mathrm{t} 0}$ to $0.77 \sigma_{\mathrm{t} 0}$ in place of $0.80 \sigma_{\text {to }}$

The concrete ultimate tensile strength was estimated by using the following equation proposed by Wang et al. [33] and Genikomsou and Polak [34]:

$$
f_{\mathrm{t}}^{\prime}=0.33 \sqrt{f_{\mathrm{c}}^{\prime}}(\mathrm{MPa}) \text {. }
$$

2.4. Modelling of Reinforcing Bars. An isotropic linear elastic behavior was assumed to model the GFRP bars in ABAQUS, up to failure without applying any damage criterion $[35,36]$. The linear elastic behavior of GFRP reinforcing bars was assumed because of the reason that they show brittle failure after yielding without going to the plastic range as shown in Figure 6.

The nonlinear behavior of steel bars was simulated as a bilinear elastoplastic material using a strain hardening ratio of 0.01 , as recommended by Kachlakev and Miller [37]. The bilinear stress-strain model for the longitudinal steel bars is shown in Figure 7.

Two-noded deformable truss elements having three DOF (translations in $X, Y$, and $Z$ global coordinate directions) at each node (T3D2R) were utilized for the simulations of all reinforcing bars. Only four parameters were needed for modelling of reinforcing bars which are Poisson's ratio $(\nu)$ and modulus of elasticity for elastic behavior and yield strength and corresponding plastic strain for plastic behavior of steel bars. In this study, Poisson's ratio $(\nu)$ was assumed as 0.3 for steel bars and 0.25 for GFRP bars [35]. The physical properties of GFRP and steel bars used in this research are given in Tables 3 and 4, respectively.

2.5. Calibration and Convergence of Model. For the convergence and validation of the finite element model and to investigate the role of various geometric and material parameters to produce accurate results, the effect of varying the mesh size, element types, dilation angle, shape factor, eccentricity, stress ratio, and viscosity parameter was studied. This calibration process was done based on the test results of control specimen S45-150. The calibrated FE model was then used to conduct the numerical analysis of all remaining column specimens.

The effect of the viscosity parameter on the loaddeflection response of columns is shown in Figure 8. The value of the viscosity parameter is influenced by time 


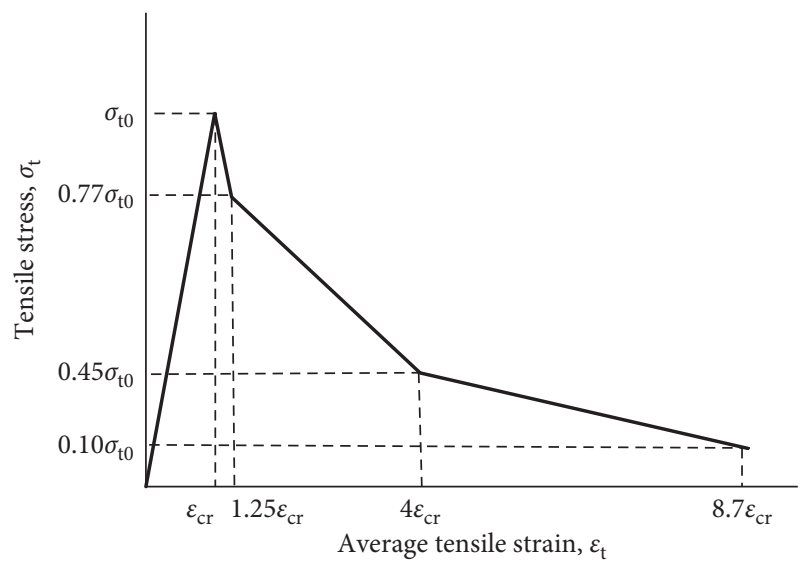

Figure 5: Modified tension stiffening model.

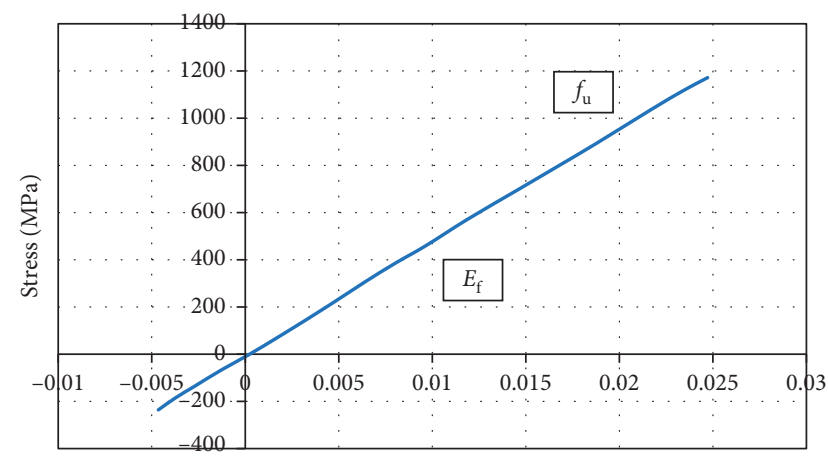

Strain $(\mathrm{mm} / \mathrm{mm})$

FIGURE 6: Linear elastic stress-strain behavior of GFRP bars.

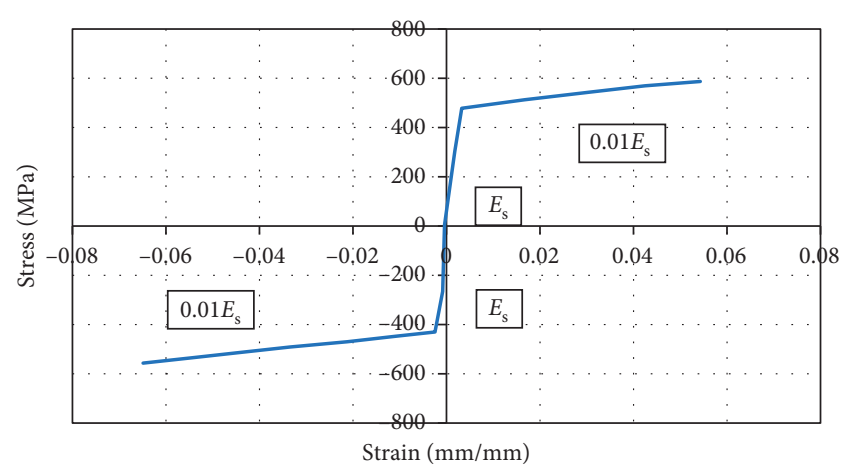

FIGURE 7: Bilinear stress-strain behavior of steel bars.

TABle 3: Physical characteristics of GFRP bars.

\begin{tabular}{lccccc}
\hline $\begin{array}{c}\text { Bar } \\
\text { no. }\end{array}$ & $\begin{array}{c}\text { Bar } \\
\text { diameter } \\
(\mathrm{mm})\end{array}$ & $\begin{array}{c}\text { Cross- } \\
\text { sectional } \\
\text { area }\left(\mathrm{mm}^{2}\right)\end{array}$ & $\begin{array}{c}\text { Young's } \\
\text { modulus } \\
(\mathrm{GPa})\end{array}$ & $\begin{array}{c}\text { Density } \\
\left(\text { ton } / \mathrm{mm}^{3}\right)\end{array}$ & $\begin{array}{c}\text { Tensile } \\
\text { strength } \\
(\mathrm{MPa})\end{array}$ \\
\hline$\# 2$ & 6.35 & 31.65 & 46.1 & $2.1 \times 10^{-9}$ & 784 \\
$\# 4$ & 14.6 & 168 & 50 & & 1200 \\
\hline
\end{tabular}

increment size. To achieve the best results, small values of the viscosity parameter should be used as compared with the pseudotime of finite element analysis and it should be taken
TABle 4: Physical characteristics of steel bars.

\begin{tabular}{lccccc}
\hline $\begin{array}{l}\text { Bar } \\
\text { no. }\end{array}$ & $\begin{array}{c}\text { Bar } \\
\text { diameter } \\
(\mathrm{mm})\end{array}$ & $\begin{array}{c}\text { Cross- } \\
\text { sectional } \\
\text { area }\left(\mathrm{mm}^{2}\right)\end{array}$ & $\begin{array}{c}\text { Young's } \\
\text { modulus } \\
(\mathrm{GPa})\end{array}$ & $\begin{array}{c}\text { Density } \\
\left(\text { ton } / \mathrm{mm}^{3}\right)\end{array}$ & $\begin{array}{c}\text { Yield } \\
\text { strength } \\
(\mathrm{MPa})\end{array}$ \\
\hline R6 & 6 & 28 & 200 & $7.85 \times 10^{-9}$ & 250 \\
N12 & 12 & 110 & 200 & & 500 \\
\hline
\end{tabular}

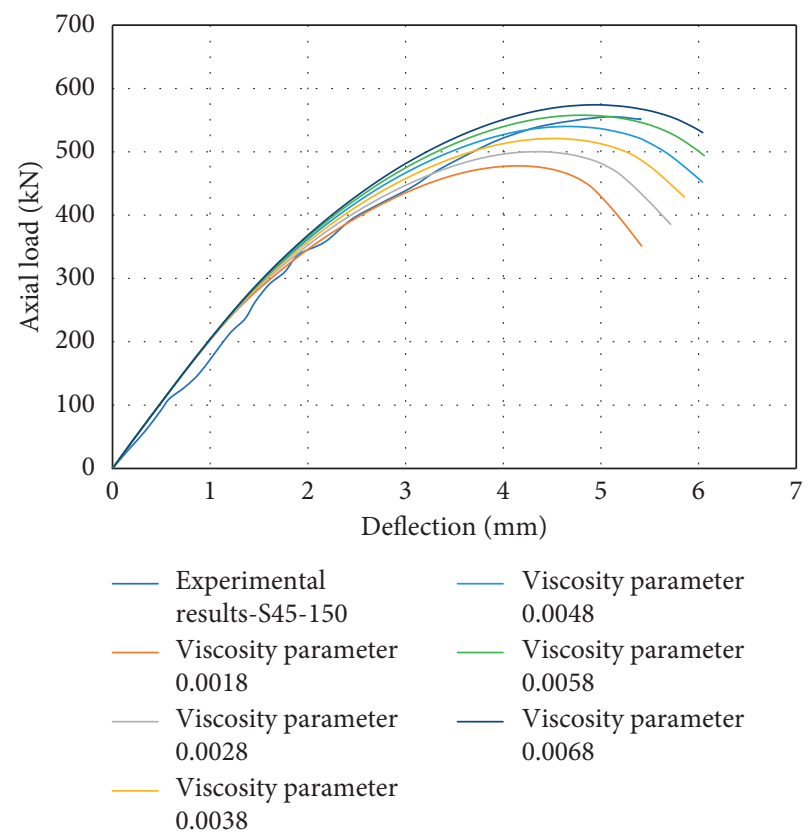

Figure 8: Axial load-axial deformation response of FEA for different values of the viscosity parameter.

near about to $15 \%$ of the time increment step to get the improved results as proposed by Lee and Fenves [38].

The time increment step was kept automatic, and initial and maximum increment sizes were kept as 0.01 throughout the analysis. The best approximate was achieved by using a value of 0.0058 for the viscosity parameter while keeping the dilation angle and mesh size of $35^{\circ}$ and $20 \mathrm{~mm}$, respectively.

For concrete, the dilation angle is a material parameter and physically, and it is interpreted as an internal friction angle of concrete. A sensitivity analysis for the dilation angle was performed to check out the parameter influence on the axial load-deflection curve of the control sample. Drucker-Prager plastic potential function is defined by the following equation:

$$
G=\sqrt{2 J_{2}}+\alpha_{\mathrm{p}} I_{1}
$$

where $\alpha_{\mathrm{p}}$ is the dilatancy parameter for concrete. The flow potential function represented by equation (9) is used by the CDP model which is Drucker-Prager hyperbolic function derived from equation (8):

$$
G(\sigma)=\sqrt{\left(\varepsilon \sigma_{\mathrm{t} 0} \tan \psi\right)^{2}+\bar{q}^{2}}-\bar{p} \tan \psi
$$

where $\psi$ is the dilation angle, $\varepsilon$ is the eccentricity of the plastic flow potential function required to adjust the shape of hyperbola, and $\sigma_{\mathrm{t} 0}$ is the uniaxial tensile strength of concrete 
at failure. By using Drucker-Prager plastic potential function (equation (8)), equation (9) can be rewritten as

$$
G(\sigma)=\sqrt{\left(\varepsilon \sigma_{\mathrm{t} 0} \tan \psi\right)^{2}+\bar{q}^{2}}+\frac{1}{3} I_{1} \tan \psi .
$$

For $\alpha_{\mathrm{p}}=0.2$ as defined by Lee and Fenves [39], the value of the dilation angle $\psi$ is $31^{\circ}$. Voyiadjis and Taqieddin [40] and $\mathrm{Wu}$ et al. [41] proposed that the value of dilatancy parameter $\alpha_{\mathrm{p}}$ ranges between 0.2 and 0.3 . For this range of $\alpha_{\mathrm{p}}$, the dilation angle $(\psi)$ should be between $31^{\circ}$ and $42^{\circ}$. In the present study, the dilation angle values between $30^{\circ}$ and $45^{\circ}$ were examined giving accurate results to previous experimental data at $35^{\circ}$ when the viscosity parameter was 0.0058 and mesh size was $20 \mathrm{~mm}$. So, dilation angle of $35^{\circ}$ was used for the finite element (FE) simulations of all specimens.

Figure 9 shows the effect of the dilation angle on the axial load-axial deformation curve for the control specimen (S45150). It can be noted from the load-deflection curve that the influence of the variation of dilation angle on results is relatively small as compared with the effect of the viscosity parameter.

The effect of variation of the shape factor $\left(K_{\mathrm{c}}\right)$ on the load-deflection behavior of the control specimen was shown in Figure 10. It was observed that, by increasing the value of $K_{c}$, the peak of the load-deflection curve moves downwards giving more error. Thus, $K_{\mathrm{c}}$ with a value of 0.667 is best suited for the plastic behavior of concrete which is also recommended by the CDP model.

The effect of the plastic potential eccentricity was also checked on the load-deflection behavior of the control specimen. It was observed that the effect of variation of eccentricity on the load-deflection behavior of columns is negligible, as shown in Figure 11. Thus, the default value of this parameter was selected in the present study. The calibration for the stress ratio $\left(\sigma_{\mathrm{b} 0} / \sigma_{\mathrm{c} 0}\right)$ was done giving the negligible effect of variation, and hence, a default value of 1.16 was selected as recommended by the ABAQUS user manual 6.10. The effect of the variation of the stress ratio was presented in Figure 12.

The convergence due to the mesh size and mesh type was also studied. The numerical model is mesh size dependent due to the strain localization which occurs within a few elements leaving the remaining elements to be unloaded. Due to use of finer mesh size, the formation of narrow bands of localization occurs and numerical convergence of the equations fails [34]. With coarse mesh sizes, the obtained results showed a significant divergence from experimental results which was not accepted. To converge these results, close to experimental results, finer mesh sizes were used. Furthermore, an even finer mesh size gave the results which were approximately the same as given by the previous mesh size used, but the time of analysis was increased for computations.

In Figure 13, the numerical results of the load-deflection curve for the control specimen are presented with $60 \mathrm{~mm}$, $50 \mathrm{~mm}, 40 \mathrm{~mm}, 30 \mathrm{~mm}, 25 \mathrm{~mm}, 20 \mathrm{~mm}$, and $15 \mathrm{~mm}$ mesh sizes. Figure 13 depicts that the mesh size of $20 \mathrm{~mm}$ is finer
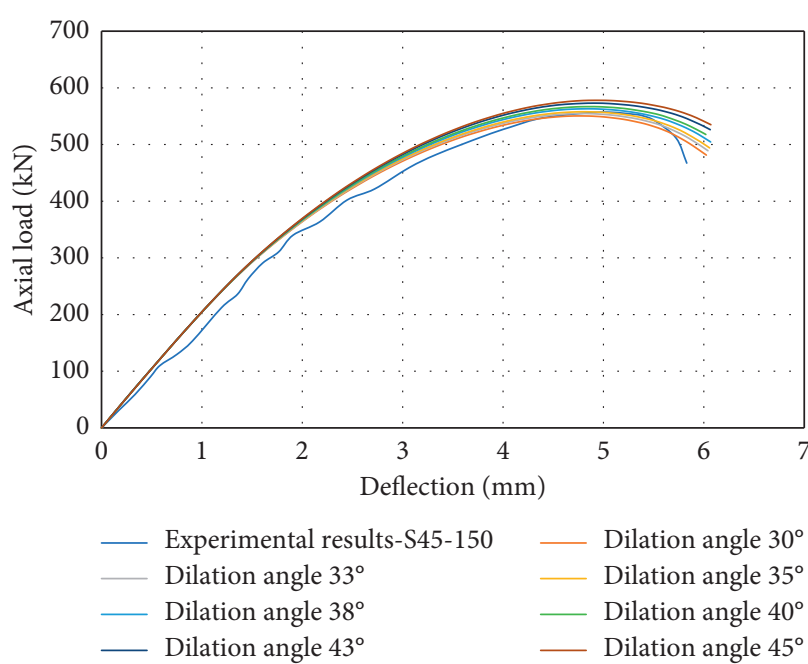

FIgURE 9: Axial load-axial deformation behavior of FEA for different values of dilation angle.

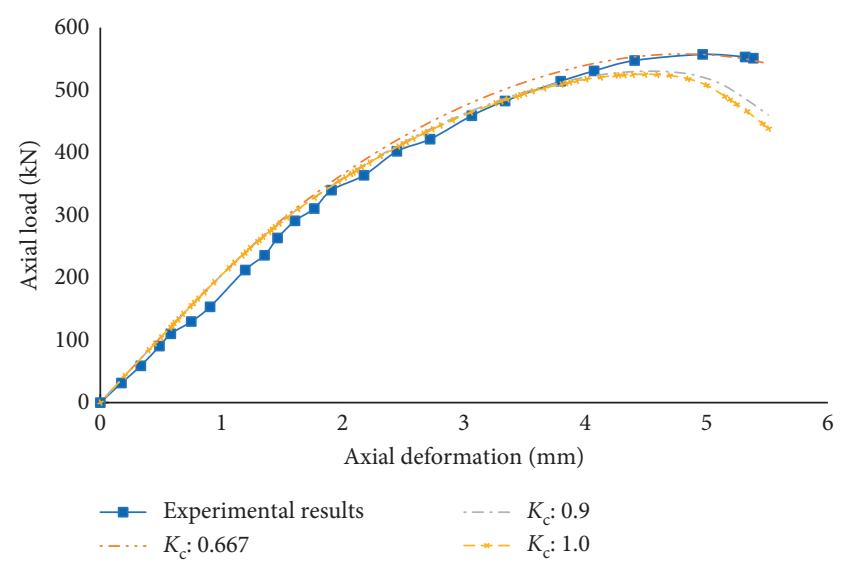

FIgURE 10: Axial load-axial deformation behavior of FEA for different values of the shape factor.

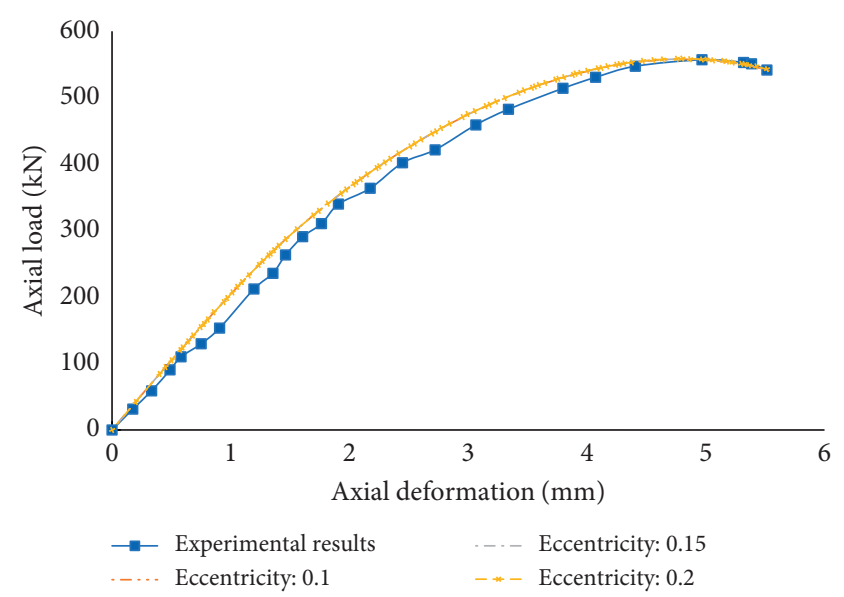

FIgURE 11: Axial load-axial deformation behavior of FEA for different values of eccentricity. 


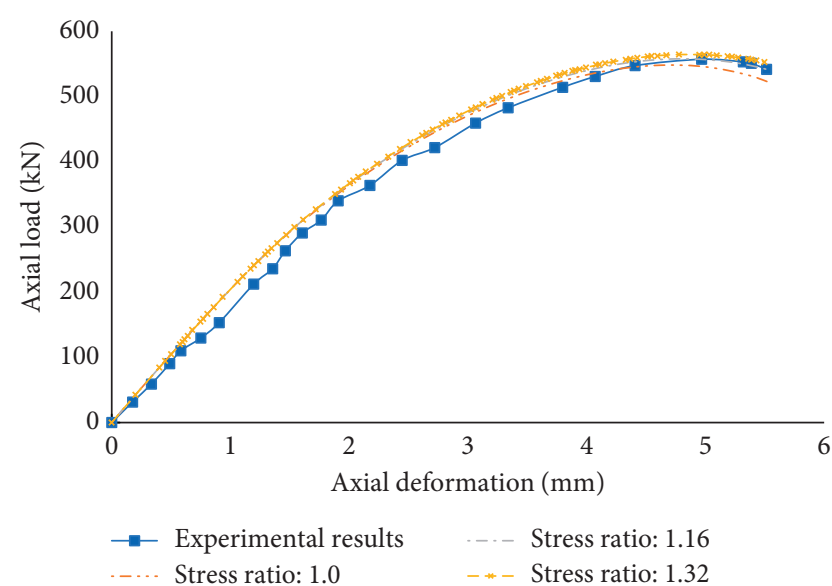

Figure 12: Axial load-axial deformation behavior of FEA for different values of stress ratio.

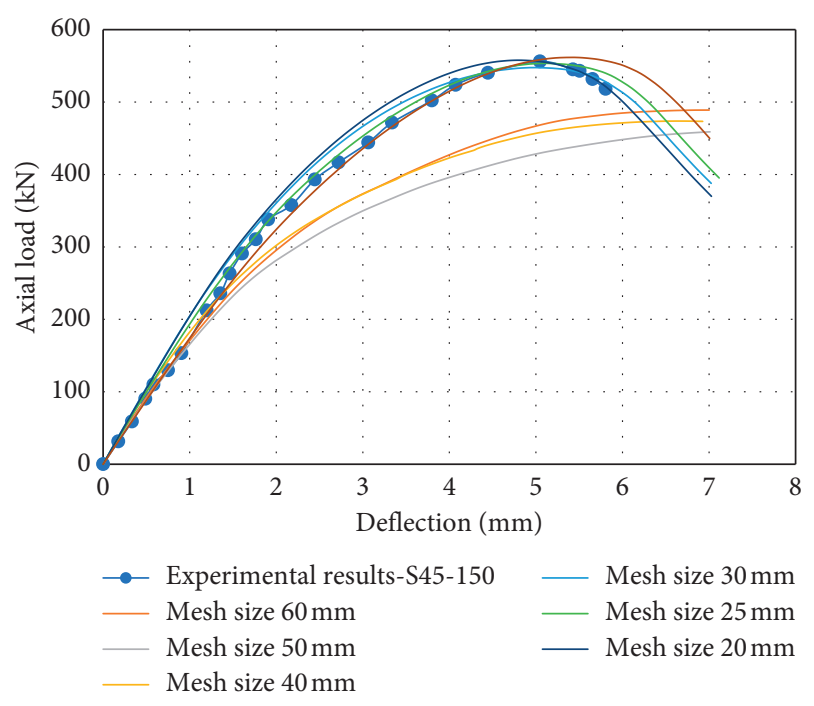

Figure 13: Axial load-axial deformation response of FEA for different values of mesh size.

enough to achieve accurate results. Small time increments were used in the study to overcome the convergence difficulties during nonlinear analysis and to make sure that the analysis will be done according to the load-deflection curve.

The convergence of the FEA model due to element types of concrete and reinforcing bars is shown in Figure 14. The calibration of the concrete material was done for standard 3D stress linear and quadratic hexahedral elements with reduced integration (C3D8R and C3D20R), triangular prism elements with hybrid formulation $(\mathrm{C} 3 \mathrm{D} 6 \mathrm{H}$ and $\mathrm{C} 3 \mathrm{D} 15 \mathrm{H})$, and linear and quadratic tetrahedral elements with hybrid formulation $(\mathrm{C} 3 \mathrm{D} 4 \mathrm{H}$ and $\mathrm{C} 3 \mathrm{D} 10 \mathrm{H})$, and the calibration of reinforcing bars was done using standard 3D truss elements with reduced integration (T3D2R and T3D3R) and beam elements with hybrid formulation $(\mathrm{B} 31 \mathrm{H}$ and $\mathrm{B} 32 \mathrm{H})$. The analysis time was captured to be less for C3D8R and T3D2R elements with relatively accurate results. Furthermore, the previous research $[12,42,43]$ has shown that C3D8R elements follow constitutive law of integration accurately and usually it is the most suitable element type for the nonlinear analysis of structures. Generally, hexahedral truss elements have preference over beam elements because of their simple geometry with accurate results and less time of analysis. Furthermore, the nodes of hexahedral elements of the concrete material are kinematically constrained to hexahedral truss elements of reinforcing bars in the embedded region constraint of ABAQUS. Therefore, the average displacements of nodes of concrete hexahedral elements and truss hexahedral elements of bars will be equal and give accurate results, and thus, these element types were used in this study giving the accuracy. It was noted that the effect of variation of 3D linear stress elements of the concrete and 3D truss elements of the reinforcement on the load-deflection curve was very less, but quadratic elements of concrete and beam elements of reinforcing bars presented some discrepancy from experimental results.

The concrete damaged plasticity model parameters, such as the dilation angle, flow potential eccentricity, the ratio of biaxial to uniaxial compressive stresses, viscosity parameter, and shape factor for yielding surface of concrete, are taken according to Table 5.

\section{Discussion of Finite Element Analysis Results}

The testing positions and boundary conditions of concentric and eccentric column specimens are shown in Figure 15 with $0 \mathrm{~mm}, 25 \mathrm{~mm}$, and $45 \mathrm{~mm}$ eccentricities, respectively. The detailed summary of the experimental test results of 13 rectangular concrete columns from Elchalakani and $\mathrm{Ma}$ [16] and finite element analysis (FEA) results from the current study are presented in Figure 16 in terms of ultimate loads and axial deflection at ultimate loads.

3.1. Control Specimen (S45-150). The final axial loaddeformation results for control specimen S45-150 are represented by Figure 17 after the calibration for different materials and geometric parameters. It showed that the experimental results of ultimate loads and deformations were traced precisely by the FEA model. The discrepancies for the control specimen were $1.58 \%$ and $14 \%$ for ultimate load and corresponding deflection, respectively.

3.2. Ultimate Load and Axial Deflection at Ultimate Load. The finite element model, calibrated for different parameters, was applied to analyze the remaining compression members. Most of the columns were traced accurately up to peak loads. The finite element models of steel-reinforced columns achieved an average difference of $3.86 \%$ in ultimate load and $15.20 \%$ in axial deflection at ultimate load and that of GFRP-reinforced columns achieved an average difference of $3.78 \%$ in ultimate load and $18.54 \%$ in corresponding axial deflection at ultimate load as compared with experimental results. However, the finite element models of concentrically loaded columns (SC-75, SC-150, GC-75, GC-150, and GC250) had a tendency of overestimation of the ultimate loads and deflections at ultimate loads. From eccentrically loaded columns, the overestimation of ultimate load only occurred 

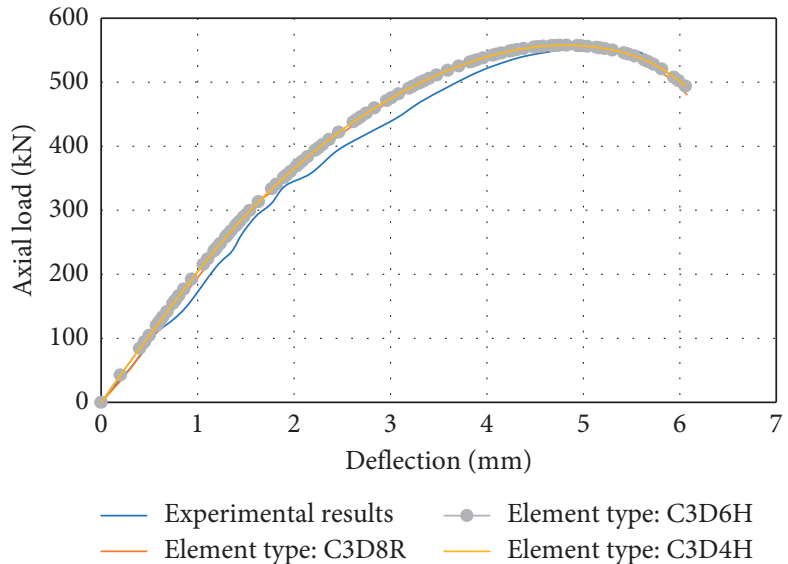

(a)

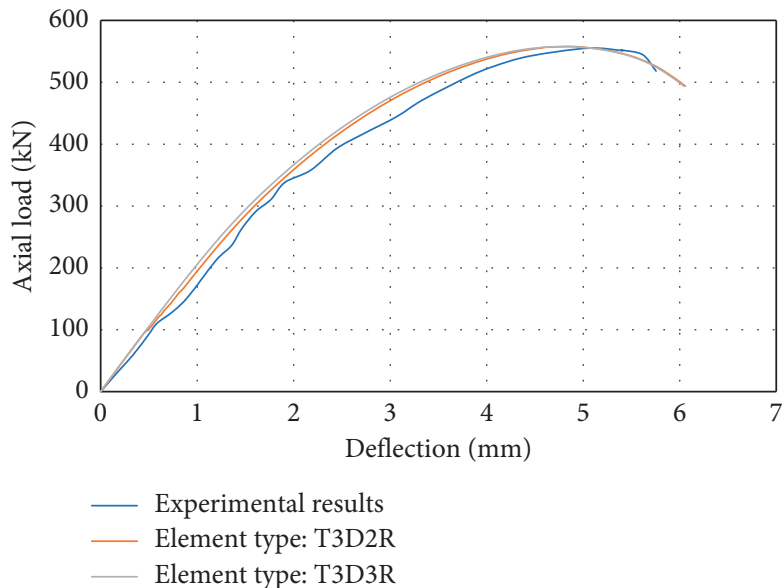

(c)

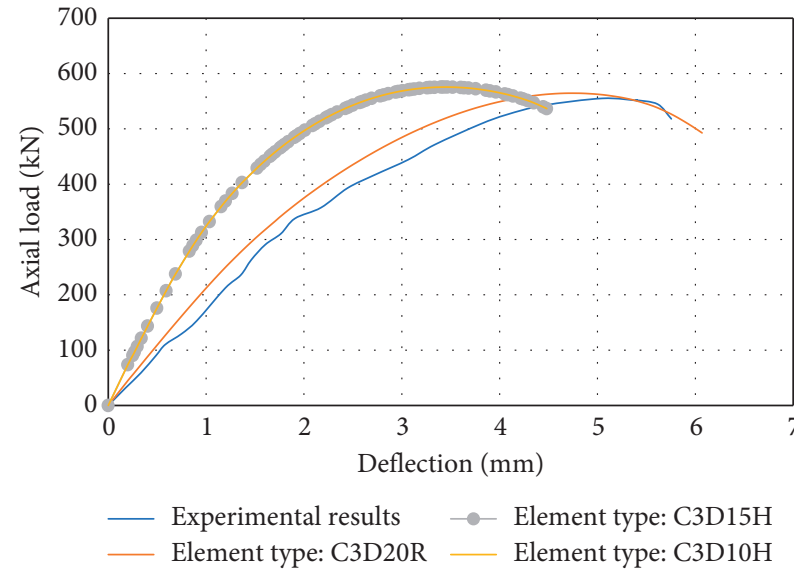

(b)

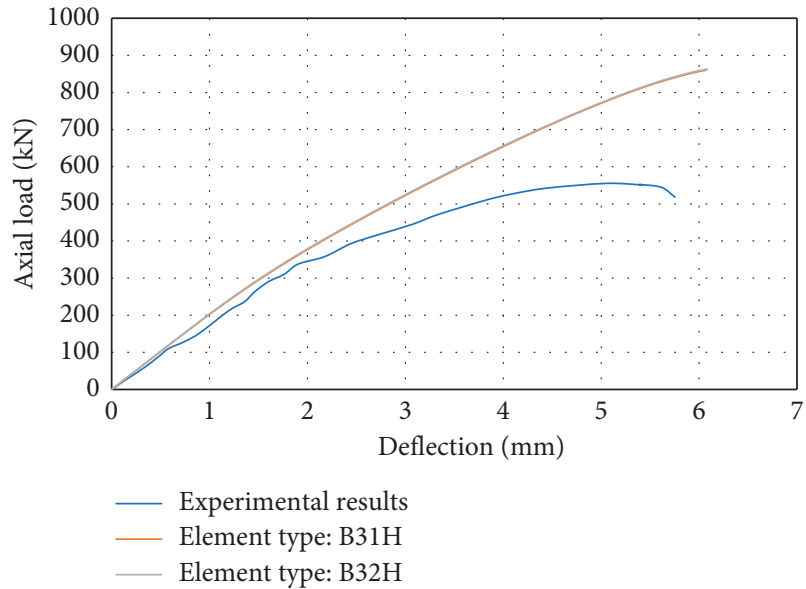

(d)

Figure 14: Axial load-axial deformation response of FEA for (a) concrete linear 3D stress elements, (b) concrete quadratic 3D stress elements, (c) truss elements of reinforcing bars, and (d) beam elements of reinforcing bars.

TABLE 5: CDP model input parameters.

\begin{tabular}{lc}
\hline Plasticity parameter & Value used in model \\
\hline Viscosity parameter & 0.0058 \\
Shape factor $\left(K_{\mathrm{c}}\right)$ & 0.667 \\
Dilation angle $(\psi)$ & $35^{\circ}$ \\
Eccentricity $(\varepsilon)$ & 0.1 \\
Stress ratio $\left(\sigma_{\mathrm{b} 0} / \sigma_{\mathrm{c} 0}\right)$ & 1.16 \\
\hline
\end{tabular}

for G25-150. The most significant discrepancy in the finite element simulations of columns was observed for S35-75 with $13.57 \%$ difference in ultimate load and for SC-75 with $27.07 \%$ difference in axial deflection at ultimate load from experimental results.

\subsection{Load-Deflection Behavior of Steel-Reinforced Columns}

3.3.1. Concentrically Loaded Columns. Figure 18 shows the experimental and finite element analysis results of loaddeflection curves for concentric steel-reinforced rectangular concrete columns with stirrups spacings of $150 \mathrm{~mm}$ and $75 \mathrm{~mm}$.
It is clear from Figure 18 that FEA results of steel RC concentric columns were in close agreement with experimental results up to peak behavior. After peak loading, FEA results were a little bit larger than experimental results. This may occur because of the assumption of a perfect bond between the reinforcing bars and concrete. The concentric column specimen SC-75 showed a difference of $1.79 \%$ in ultimate load and $27.07 \%$ in the corresponding deflection as compared with experimental results. On the contrary, SC150 showed a difference of $0.56 \%$ and $21.28 \%$ in ultimate load and axial deflection at ultimate load, respectively.

3.3.2. Eccentrically Loaded Columns. The axial load-axial deflection curves for eccentric steel-reinforced rectangular concrete columns with ligature spacings of $150 \mathrm{~mm}$ and $75 \mathrm{~mm}$ and test eccentricities of $25 \mathrm{~mm}, 35 \mathrm{~mm}$, and $45 \mathrm{~mm}$ are shown in Figure 19. The FEA results of eccentric columns were in high accuracy with experimental test results in the elastic range. The ultimate loads given by FEA simulations were a little bit less than the experimental results for all the eccentric loaded steel-reinforced columns. 


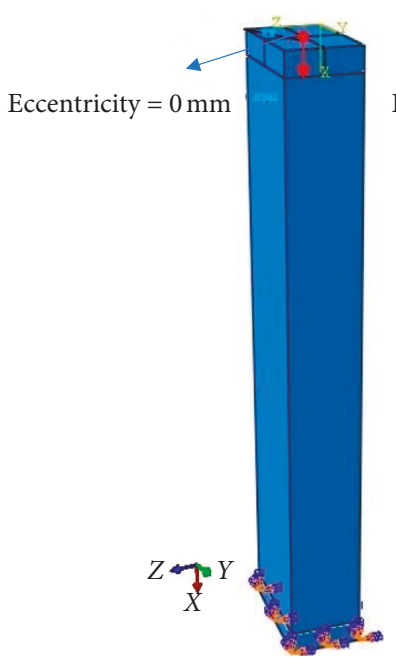

(a)

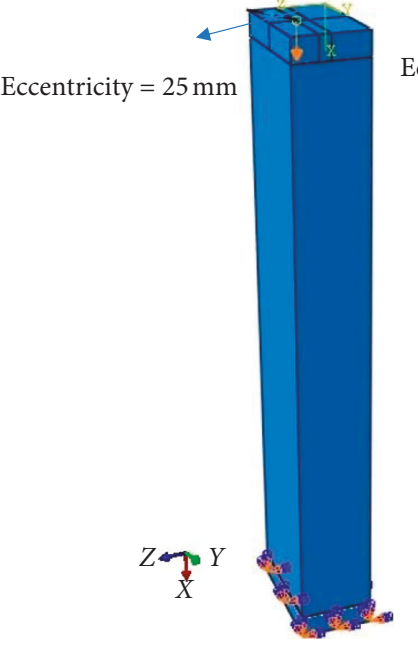

(b)

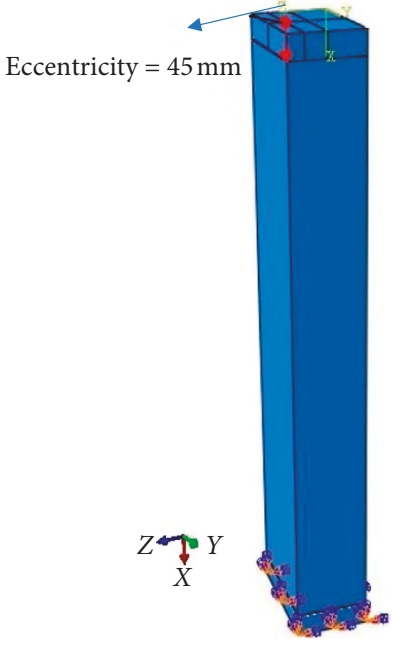

(c)

Figure 15: Testing and boundary conditions for concentric columns at (a) $0 \mathrm{~mm}$, (b) $25 \mathrm{~mm}$, (c) and $45 \mathrm{~mm}$.

The finite element simulations produced results such that the differences of $0.31 \%$ and $13.57 \%$ were observed for ultimate loads and the differences of $17.48 \%$ and $2.40 \%$ were observed for axial deflections at ultimate loads for specimens S25-75 and S35-75, respectively. The numerical simulations of columns with $150 \mathrm{~mm}$ ligature spacing (S25-150 and S45150) gave discrepancy of $5.34 \%$ and $1.58 \%$ for ultimate loads and $8.94 \%$ and $14.06 \%$ for corresponding axial deflection at ultimate load, respectively. The behavior of eccentric columns was traced better as compared with concentric columns.

3.3.3. Ultimate Load against Eccentricity. Figure 20 represents the ultimate loads of steel-reinforced columns as a function of the test eccentricity level. It represents that the ultimate load decreases as the test eccentricity of columns increases. The decrease in ultimate load with an increase of eccentricity is somewhat larger for FEA results. When eccentricity level increases, the longitudinal compressive stresses increase on that side of columns causing the buckling of columns and, consequently, columns fail at lower loads. From Figure 20, one can observe that when FEA load is applied with an eccentricity equal to $25 \mathrm{~mm}$, there is a reduction of ultimate load up to roughly $700 \mathrm{kN}$ and when FEA load is applied with an eccentricity equivalent to $45 \mathrm{~mm}$, there is an ultimate load reduction of roughly $900 \mathrm{kN}$.

So, it can be monitored that a loss of $43.86 \%$ and $64.26 \%$ in ultimate load occurs for $25 \mathrm{~mm}$ and $45 \mathrm{~mm}$ eccentricities, respectively, when compared to an identical concentrically loaded column. Moreover, for small eccentricities within the cross-sectional kern, the reduction in ultimate load occurs with a linear trend approximately.

\subsection{Load-Deflection Behavior of GFRP-Reinforced Columns}

3.4.1. Concentrically Loaded Columns. Figure 21 represents the experimental and finite element analysis (FEA) results of load-deformation curves for GFRP-reinforced concentric concrete columns with stirrups spacings of $250 \mathrm{~mm}, 150 \mathrm{~mm}$, and $75 \mathrm{~mm}$. The finite element analysis (FEA) results of GFRP concentric columns were in good agreement with experimental behavior up to ultimate loads. After ultimate loading, FEA results were larger than experimental results with respect to both ultimate loads and deformations at ultimate loads similar to steel columns. These increased numerical results may be due to the fact that a perfect tie bond between concrete and GFRP reinforcing bars was assumed.

The concentric column specimen GC-75 showed the difference of $2.57 \%$ in ultimate load and $25.35 \%$ in the corresponding deflection as compared with experimental results. The specimen GC-150 showed discrepancy of $1.27 \%$ and $17.47 \%$ in ultimate load and axial deflection at ultimate load, respectively. The column with ligature spacing of $250 \mathrm{~mm}$ gave the differences of $1.79 \%$ in ultimate load and $21.07 \%$ in axial deflection at ultimate load. The FEA response of GC-150 was slightly stiffer than the experimental test results.

3.4.2. Eccentrically Loaded Columns. The FEA results of GFRP-reinforced eccentric columns were in high accuracy with experimental results up to peak behavior. The graphical representations of axial load against the axial deflection for eccentrically loaded GFRP-reinforced columns with tie spacings of $75 \mathrm{~mm}$ and $150 \mathrm{~mm}$ and eccentricities of $25 \mathrm{~mm}, 35 \mathrm{~mm}$, and $45 \mathrm{~mm}$ are shown in Figure 22. The ultimate loads shown by FEA simulations were a little bit less than the experimental results for all the eccentric columns except G25-150.

The finite element simulations produced results such that the difference of $2.34 \%$ was observed for ultimate load and a difference of $21.37 \%$ was observed for axial deflection at ultimate load for the specimen G25-75 as compared with experimental test results. G35-75 showed the differences of $11.84 \%$ and $17.46 \%$ for ultimate load and corresponding deflection. The numerical simulations of columns with a transverse reinforcement spacing of $150 \mathrm{~mm}$ (G25-150 and G45-150) gave discrepancy of only $0.42 \%$ and $6.23 \%$ for 

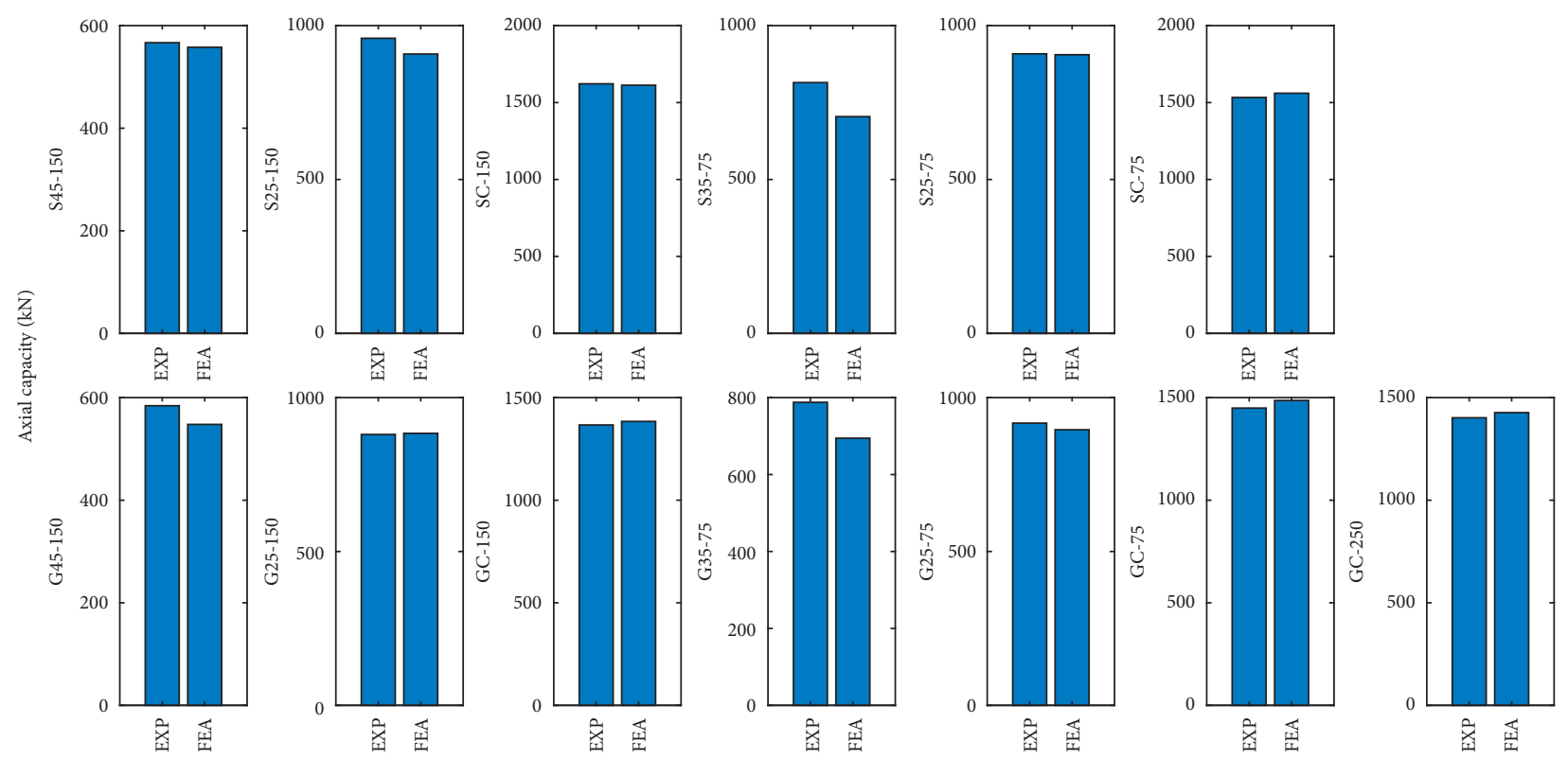

(a)
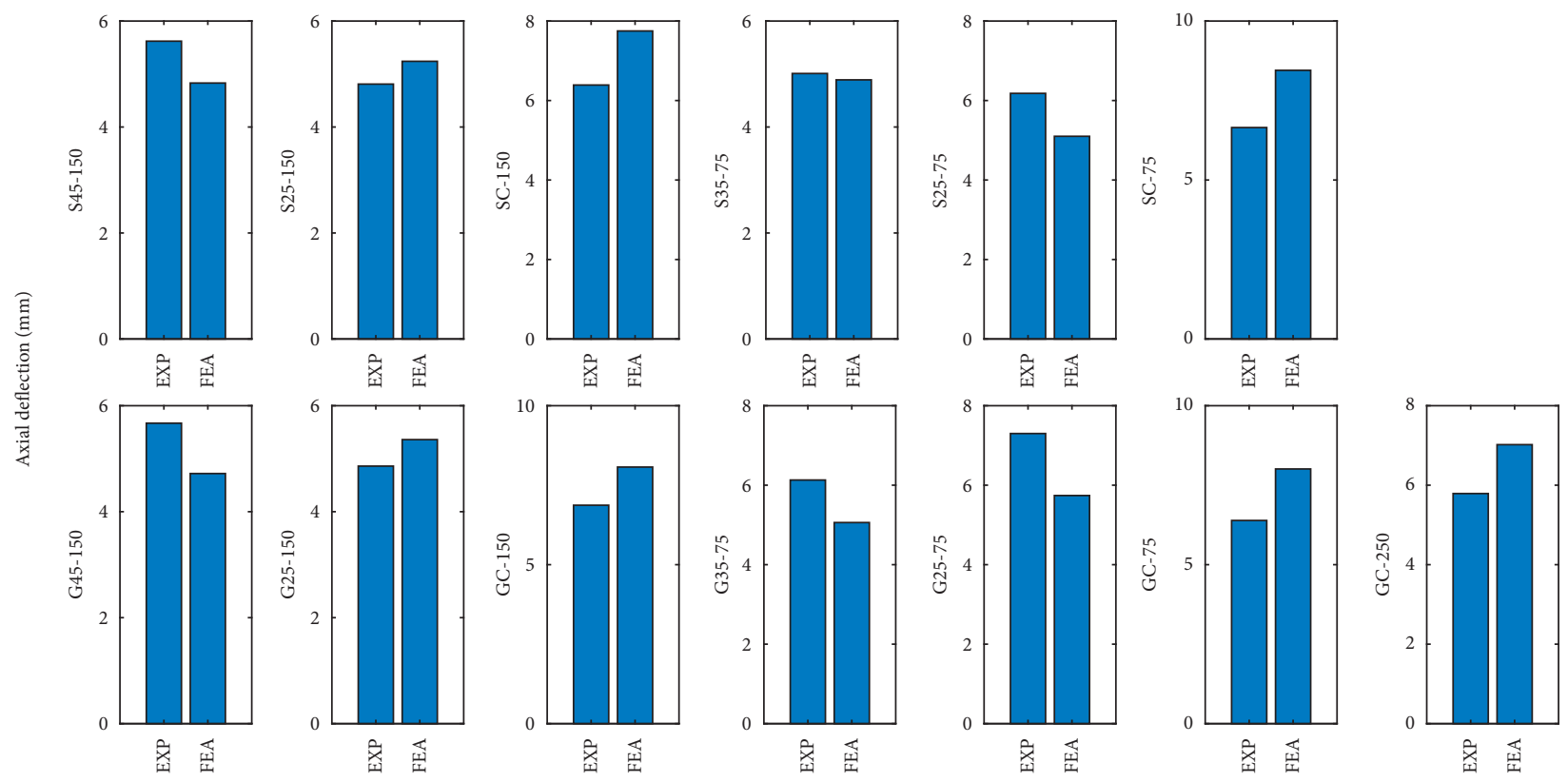

FIGURE 16: Summary of FEA results of (a) ultimate loads and (b) axial deflection at ultimate loads for column specimens from this study and experimental results from Elchalakani and Ma [16].

ultimate loads and $10.29 \%$ and $16.75 \%$ for axial deflection at ultimate load, respectively. The finite element simulations in ABAQUS Standard terminated at the points where sufficient deformation occurred in an element of the specimen. Therefore, a finer mesh is the most suitable for analysis. However, the FE simulations of ultimate load and deformation at ultimate load were conducted at a high accuracy.

3.4.3. Ultimate Load against Eccentricity. Figure 23 represents the ultimate loads of GFRP-reinforced columns as a function of testing eccentricity. It clarifies that the ultimate load is inversely proportional to the test eccentricity of columns. Due to an increase of eccentricity, the stresses increase on the either side of the column, allowing the column to buckle on that side by decreasing the axial capacity. When test eccentricity is equivalent to $25 \mathrm{~mm}$, the FEA ultimate load reduces up to roughly $600 \mathrm{kN}$ and when the load is applied with an eccentricity of $45 \mathrm{~mm}$, the reduction in FEA ultimate load is roughly $950 \mathrm{kN}$. So, it can be observed that a loss of $39.74 \%$ in ultimate load occurs for $25 \mathrm{~mm}$ eccentricity and $60.42 \%$ loss occurs for $45 \mathrm{~mm} \mathrm{ec-}$ centricity when compared to an identically loaded column. 


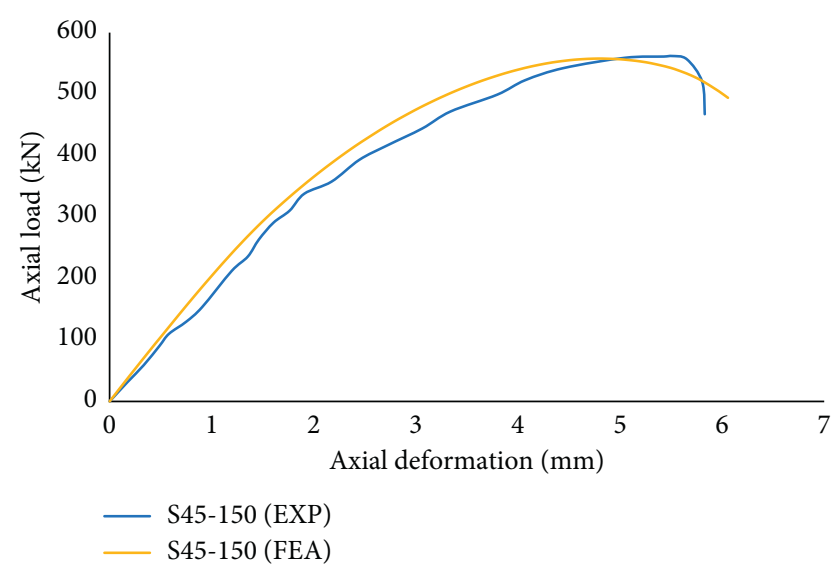

FIgURE 17: FEA and experimental load-deflection results for the control specimen.

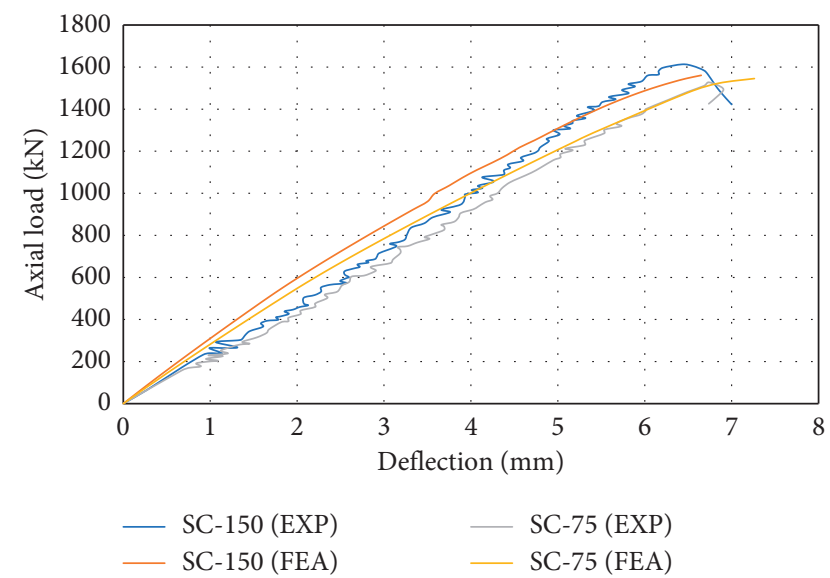

FIgURE 18: Comparison of FEA and experimental results of axial load-axial deformation for steel-reinforced concentric columns (SC-75 and SC-150).

These results show that the geometry of GFRP-reinforced beam-column connections in RC structures should be adequately simulated because a small eccentricity may cause a large reduction in ultimate loads. Moreover, it is clear from Figure 23 that the ultimate load decreases linearly as the eccentricity of columns increases. The decrease in ultimate load with an increase of the eccentricity is larger for numerical results as compared with the experimental test results.

\section{Numerical Parametric Study}

To study the influence of different variables on the loaddeflection behavior of the steel and GFRP RC columns (S45150 \& G45-150), each of the following variables was studied: (1) compressive strength of concrete $\left(f_{c}^{\prime}\right)$; (2) longitudinal reinforcement ratio $\left(\rho_{1}\right)$; $(3)$ concrete cover $(\mathrm{cc})$; and (4) cross-sectional shape of columns.

4.1. Effect of Compressive Strength of Concrete $\left(f_{c}^{\prime}\right)$. To investigate the effect of varying the compressive strength of concrete on axial load and axial deflection response of control specimens, $f_{c}^{\prime}$ of $10 \mathrm{MPa}, 20 \mathrm{MPa}, 30 \mathrm{MPa}, 40 \mathrm{MPa}$, and $50 \mathrm{MPa}$ was considered as represented in Figure 24. The compressive and tensile behavior of concrete in the CDP model was changed according to the compressive strength, but the parameters of plastic behavior were kept the same as calibrated. It was observed that the maximum ultimate capacity of the steel RC column (S45-150) increased up to 145\% and that of the GFRP RC column (G45-150) increased up to $193.6 \%$ at constant longitudinal reinforcement ratio $\left(\rho_{1}\right)$ of $1.13 \%$ when $f_{c}^{\prime}$ of concrete increased from $10 \mathrm{MPa}$ to $50 \mathrm{MPa}$. GFRP RC columns showed on average $16 \%$ less axial loadcarrying capacity as compared with their steel-reinforced concrete counterparts at $1.13 \%$ reinforcement ratio. The maximum increase in axial deflection at the ultimate axial load was $57 \%$ and $60 \%$ at $\rho_{1}$ of $1.13 \%$ by increasing the concrete strength from $10 \mathrm{MPa}$ to $50 \mathrm{MPa}$ for steel and GFRP $\mathrm{RC}$ column, respectively. The load-deflection curves showed a higher initial stiffness as $f_{c}^{\prime}$ of concrete increased.

Similarly, it was observed that the maximum ultimate capacity of the steel control specimen increased up to $193 \%$ and that of the GFRP RC column increased up to $215 \%$ at the constant concrete clear cover of $55 \mathrm{~mm}$ when $f_{\mathrm{c}}^{\prime}$ of concrete increased from $10 \mathrm{MPa}$ to $50 \mathrm{MPa}$. GFRP RC columns showed on average $6 \%$ less axial load-carrying capacity as compared with their steel-reinforced concrete counterparts at $55 \mathrm{~mm}$ concrete cover. The maximum increase in axial deflection at ultimate load was $64 \%$ at $25 \mathrm{~mm}$ concrete cover and $75 \%$ at $55 \mathrm{~mm}$ cover when concrete strength was increased from 10 to $50 \mathrm{MPa}$ for steel and GFRP RC column, respectively. The results indicated that as the concrete strength increased, the axial loading capacity of columns increased significantly.

\subsection{Effect of Longitudinal Reinforcement Ratio $\left(\rho_{l}\right)$. The 3D} plots of Figure 24 show the effect of different main reinforcements on the load and deflection behavior of steel and GFRP RC columns. Both columns (S45-150 and G45-150) had a constant transverse reinforcement of $6 \mathrm{~mm}$ diameter ties at $150 \mathrm{~mm}$ spacing with varying longitudinal reinforcement ratios of $1.13 \%, 1.63 \%, 2.90 \%, 4.09 \%$, and $5.48 \%$. The percentage increase in axial capacity was $110 \%$ and $62 \%$ at the constant concrete $f_{c}^{\prime}$ of $10 \mathrm{MPa}$ when $\rho_{1}$ ratio was increased from $1.13 \%$ to $5.48 \%$ for steel and GFRP RC specimen, respectively. When $\rho_{1}$ was increased from $1.13 \%$ to $5.48 \%$, the maximum increase of $45 \%$ and $40 \%$ in axial deflection at ultimate load occurred at $10 \mathrm{MPa}$ concrete strength for steel and GFRP RC column, respectively.

Similarly, for both types of RC specimens, a percentage increase of $110 \%$ and $60 \%$ occurred for the ultimate load at $15 \mathrm{~mm}$ cover of concrete by increasing $\rho_{1}$ from $1.13 \%$ to $5.48 \%$, respectively. GFRP RC columns presented on average 54\% and 55\% less axial capacity as compared with steel RC columns at $10 \mathrm{MPa}$ concrete strength and $15 \mathrm{~mm}$ concrete cover, respectively. The FEA results indicated that both the specimens confirmed the increase in ultimate load-carrying capacity of columns with the increase of $\rho_{1}$ ratio. The steel RC specimen showed more increase in axial capacity by increase of main reinforcement as compared with the GFRP RC specimen. 


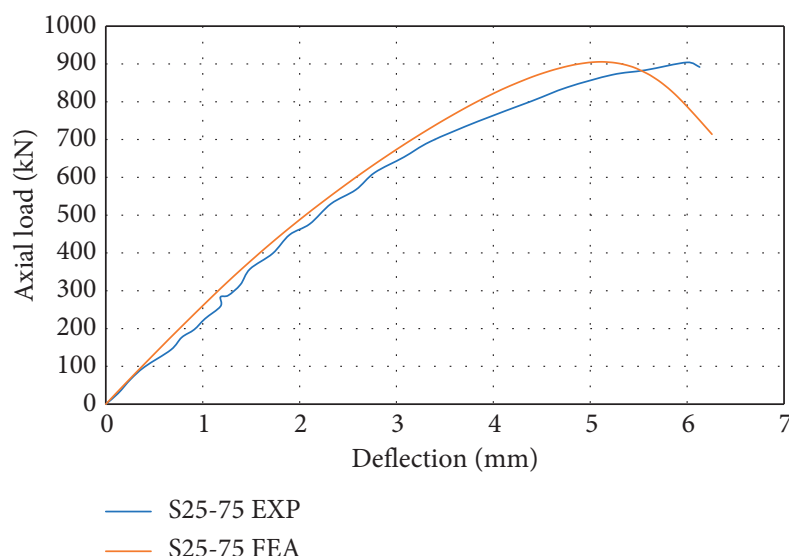

(a)

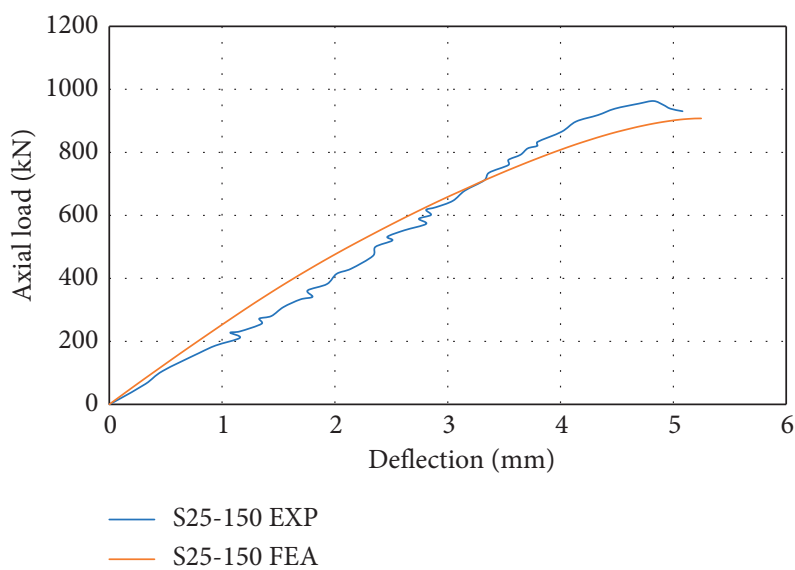

(c)

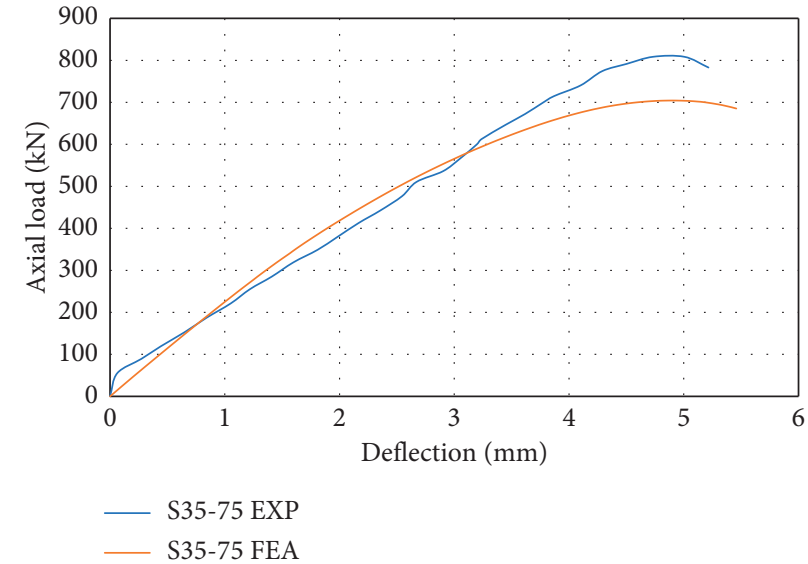

(b)

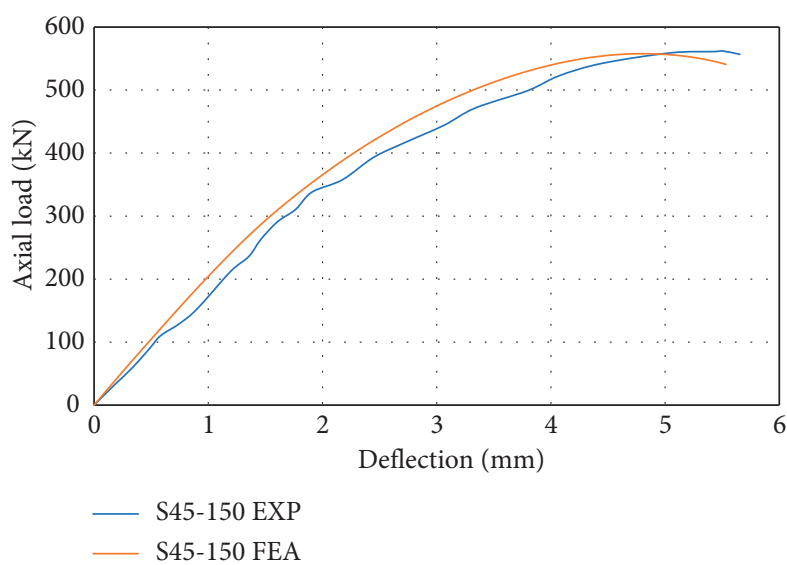

(d)

FIGURE 19: Comparison of FEA and experimental results of axial load-axial deformation for (a) S25-75, (b) S35-75, (c) S25-150, and (d) S45-150.

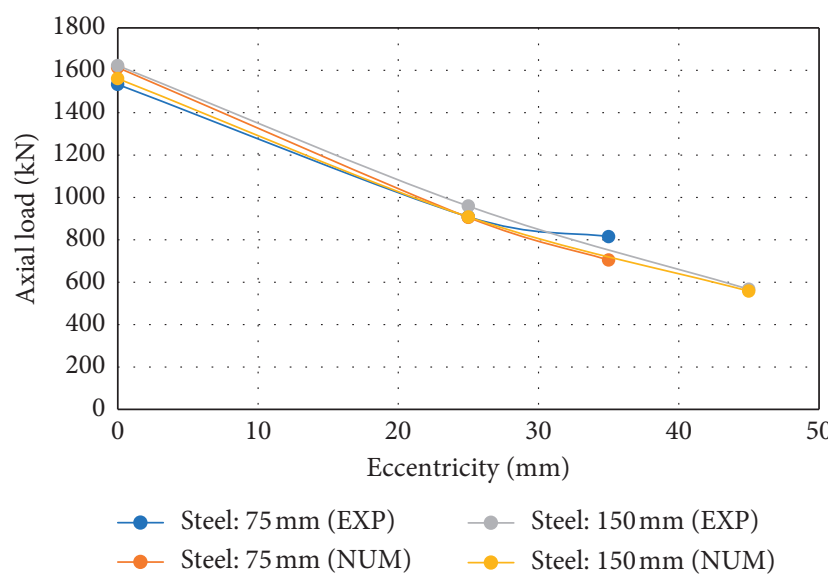

Figure 20: Experimental and numerical ultimate load vs. eccentricity for steel columns.

4.3. Effect of Concrete Cover (cc). The specimens S45-150 and G45-150 were modelled with the same transverse reinforcement of $6 \mathrm{~mm}$ diameter ties at a spacing to $150 \mathrm{~mm}$ with different concrete covers of $15 \mathrm{~mm}, 25 \mathrm{~mm}, 35 \mathrm{~mm}$, $45 \mathrm{~mm}$, and $55 \mathrm{~mm}$. It was observed that the ultimate load and axial deflection at ultimate load decreased up to $40 \%$ at

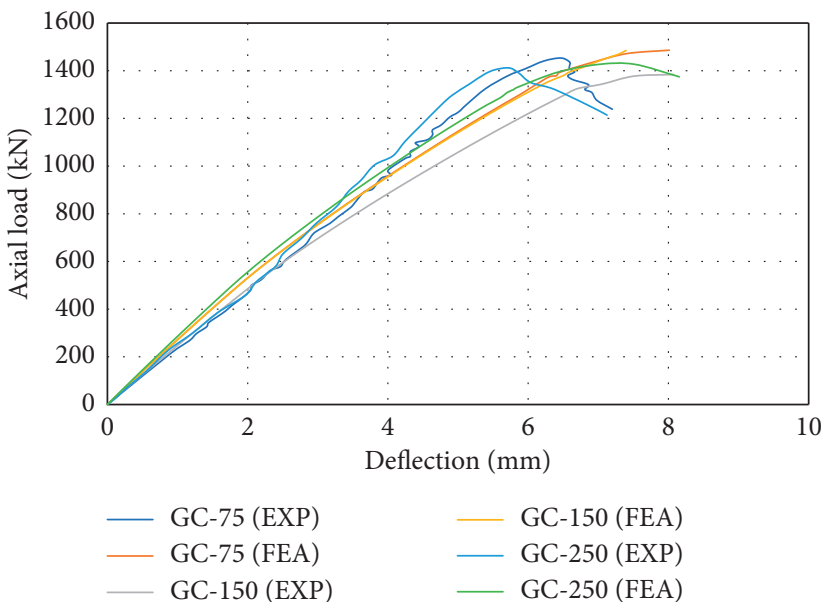

FIGURE 21: Comparison of FEA and experimental results of loaddeflection curves for GFRP-reinforced concentric columns (GC-75, GC-150, and GC-250).

$\rho_{1}$ of $5.48 \%$ and $10 \%$ at $\rho_{1}$ of $1.13 \%$ for the steel RC column and $37 \%$ at $\rho_{1}$ of $5.48 \%$ and $27 \%$ at $\rho_{1}$ of $2.90 \%$ for the GFRP RC column, respectively, when the clear concrete cover was increased from $15 \mathrm{~mm}$ to $55 \mathrm{~mm}$ as presented in Figure 24 . 


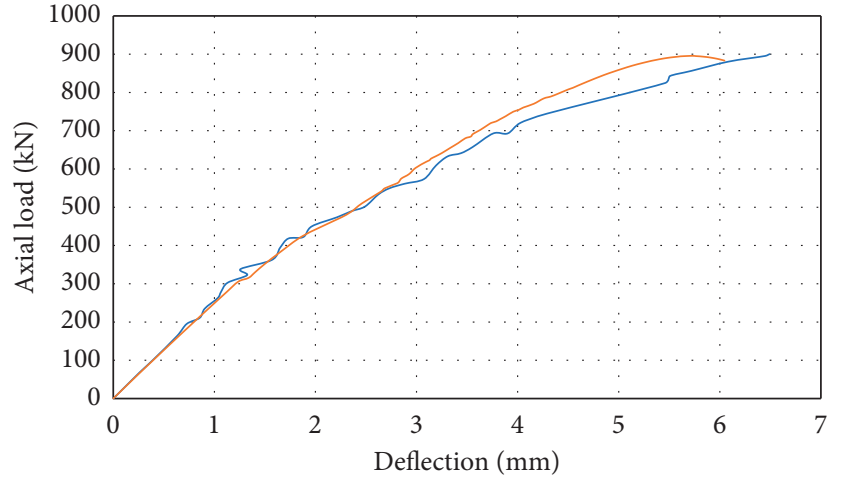

- G25-75 EXP

- G25-75 FEA

(a)

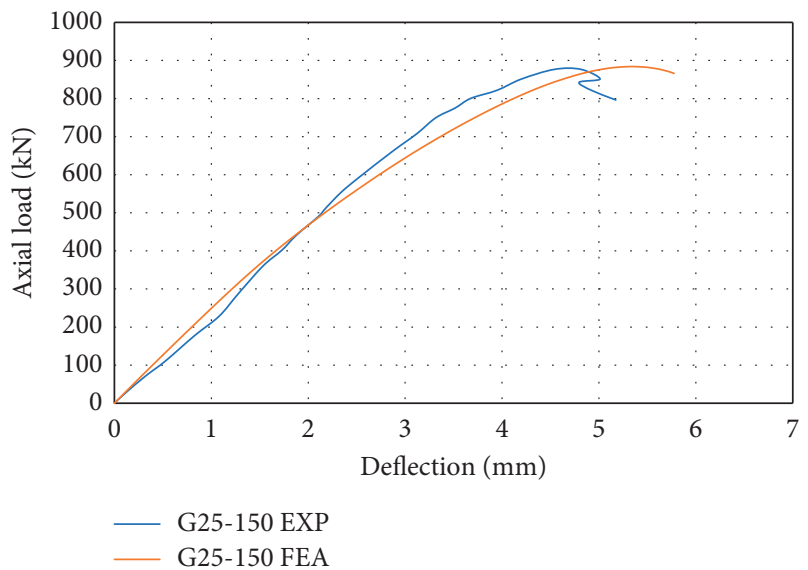

(c)

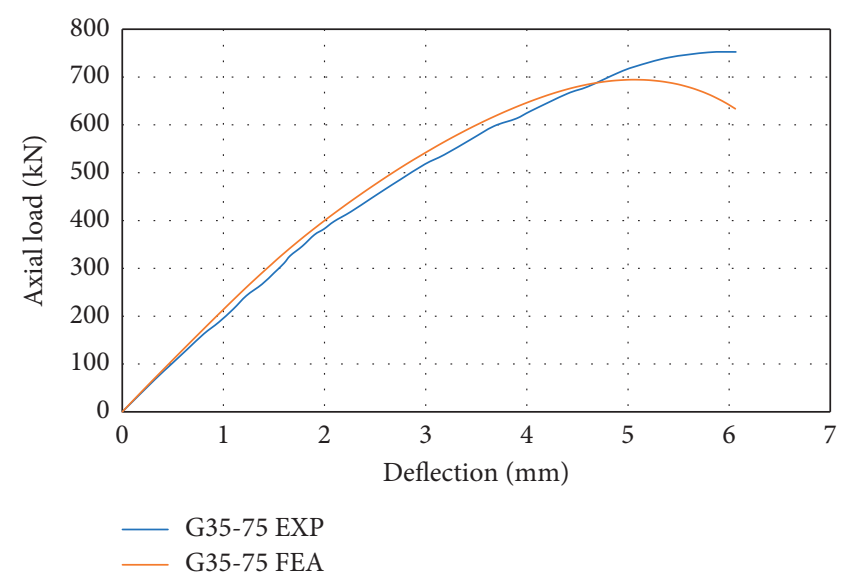

(b)

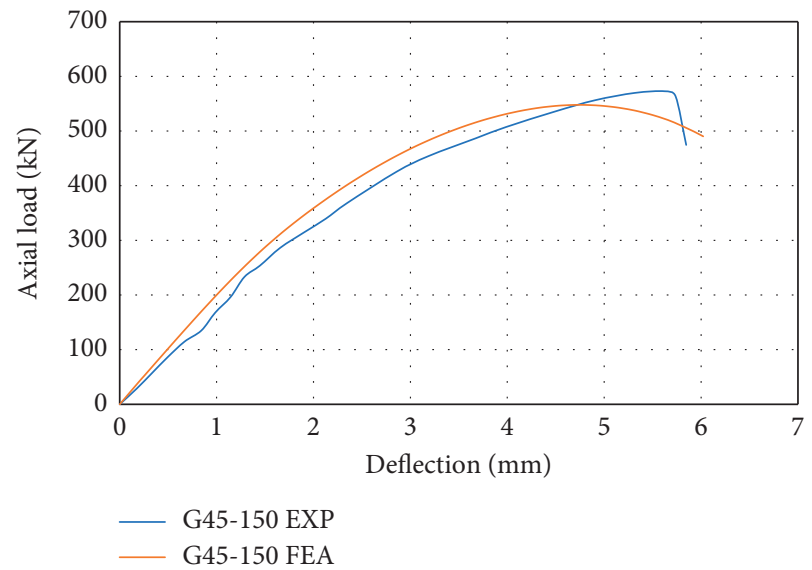

(d)

FIGURE 22: Comparison of FEA and experimental results of load-deflection curves for (a) G25-75, (b) G35-75, (c) G25-150, and (d) G45-150.

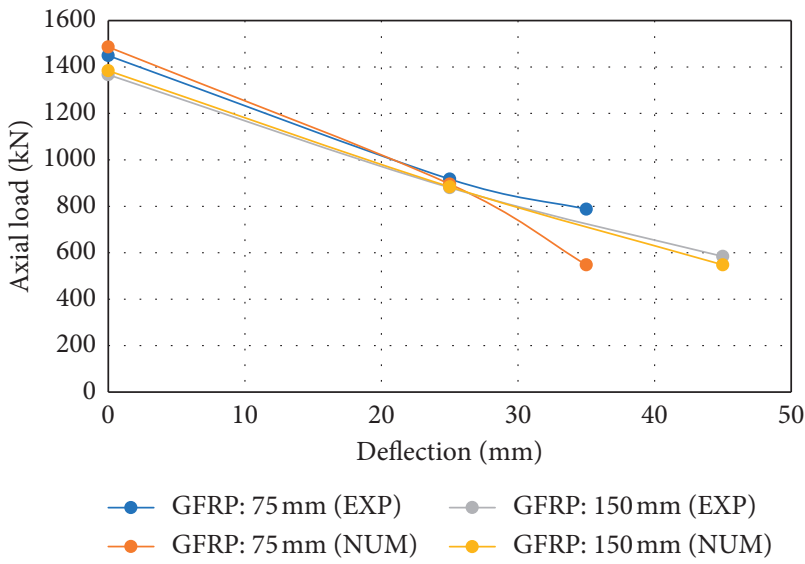

FIgURE 23: Experimental and numerical ultimate load vs. eccentricity for GFRP columns.

GFRP-reinforced columns showed on average 76\% less axial ultimate load as compared with their steel RC counterparts at $5.48 \%$ reinforcing ratio. By increasing the concrete cover, the core area of concrete decreased by providing the less bearing cross-sectional area, due to which axial capacity of the steel RC column decreased from $1005 \mathrm{kN}$ to $607 \mathrm{kN}$, and that of the GFRP RC column decreased from $580 \mathrm{kN}$ to $362 \mathrm{kN}$ when concrete cover increased from $15 \mathrm{~mm}$ to $55 \mathrm{~mm}$ at $\rho_{1}$ of $5.48 \%$.

The decrement of $26 \%$ and $13 \%$ occurred at $10 \mathrm{MPa}$ by increasing the concrete cover (cc) from $15 \mathrm{~mm}$ to $55 \mathrm{~mm}$ for steel and GFRP column, respectively. Thus, there should be a suitable concrete cover not to decrease the capacity of the column significantly and to provide sufficient resistance to corrosion of steel. Smaller concrete cover for GFRP RC columns is recommended due to corrosion resistant property of GFRP bars.

4.4. Effect of Cross-Sectional Shape. Three cross-sectional shapes of columns (rectangular, square, and circular) were considered with the same cross-sectional area of $41600 \mathrm{~mm}^{2}$, same concrete compressive strength of $32 \mathrm{MPa}$, the same reinforcements, and the same test eccentricity, as shown in Figure 25. The dimensions of rectangular, square, and circular columns modelled in ABAQUS Standard were $160 \times 260 \times 1200 \mathrm{~mm}, 204 \times 204 \times 1200 \mathrm{~mm}$, and $230 \times 1200 \mathrm{~mm}$, respectively.

It can be observed from Figure 26 that square-shaped columns were failed at relatively larger axial loads and larger 

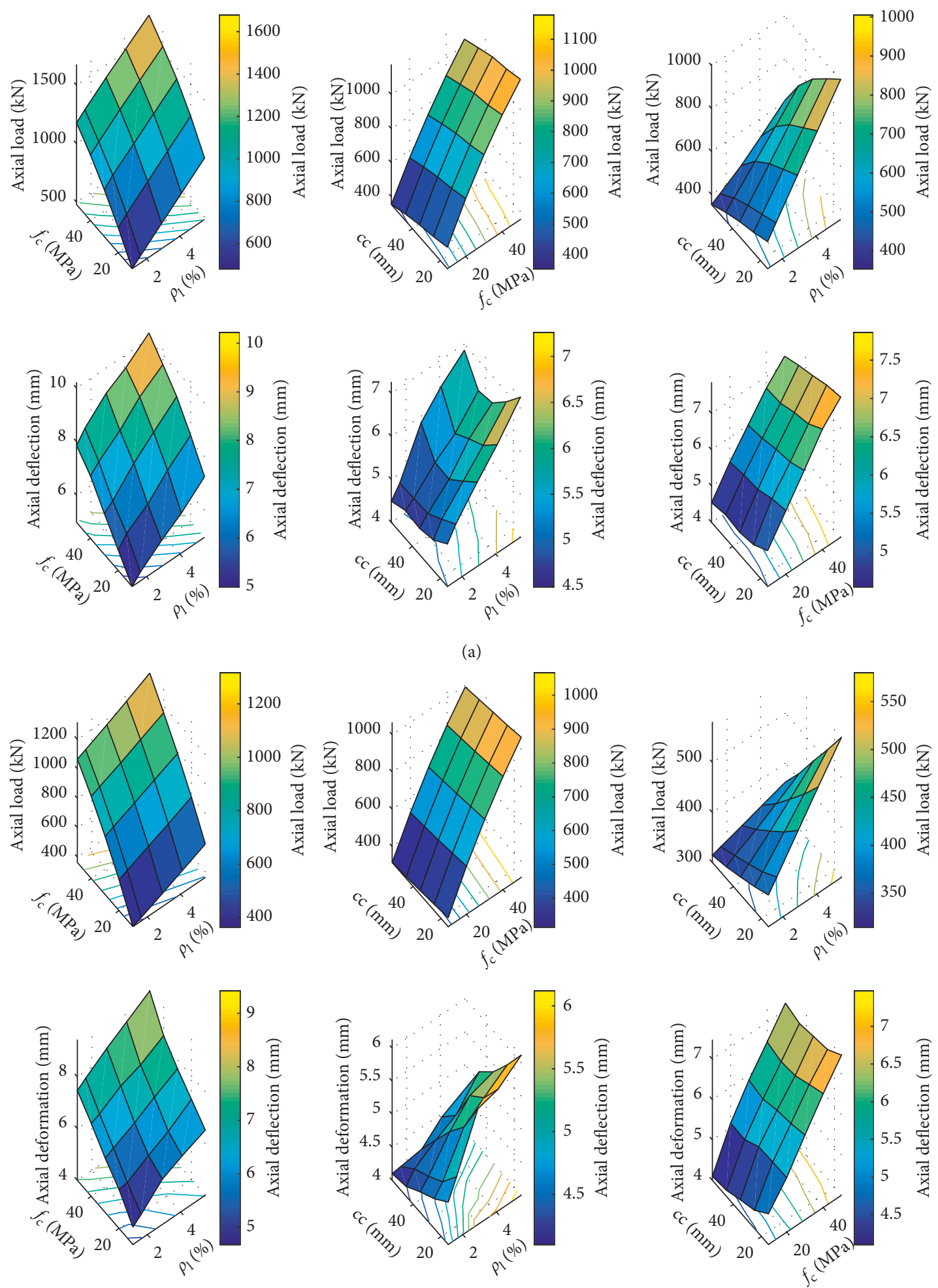

(b)

FIgURE 24: Effect of concrete compressive strength $\left(f_{\mathrm{c}}^{\prime}\right)$, concrete cover $(\mathrm{cc})$, and longitudinal reinforcement ratio $\left(\rho_{1}\right)$ on axial ultimate load and axial deflection at ultimate load of (a) steel RC column (S45-150) and (b) GFRP RC column (G45-150).

axial deflections for both steel and GFRP reinforcements. The axial capacities of steel RC square and circular columns were 1.62 and 1.54 times the axial capacity of the steel RC rectangular column. Similarly, the axial peak capacities of GFRP RC square and circular columns were 1.92 and 1.81 times the axial capacity of GFRP RC rectangular column. 


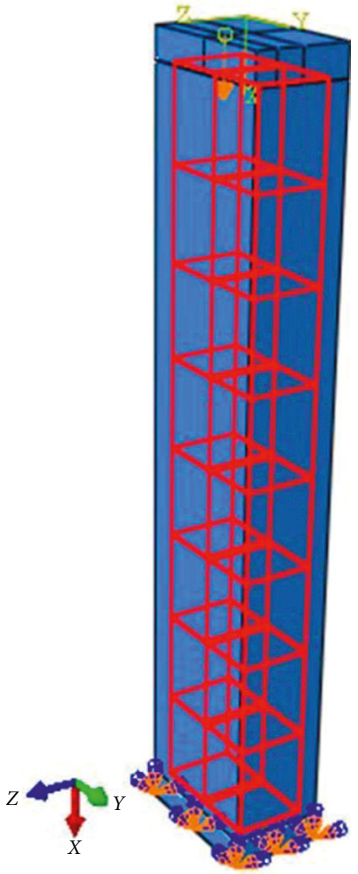

(a)

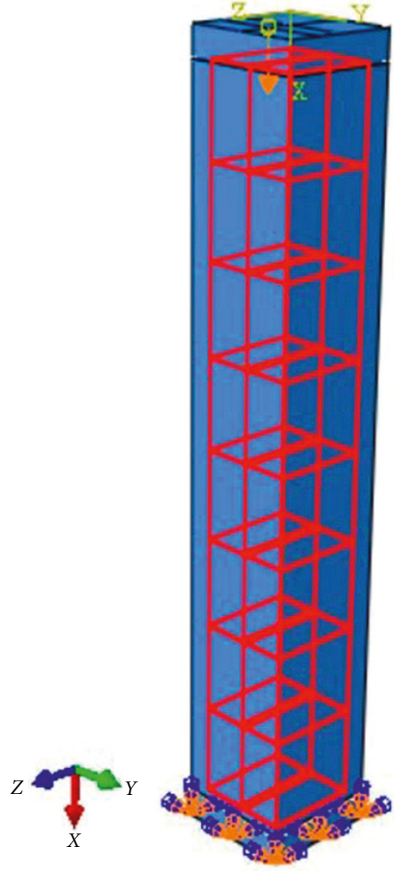

(b)

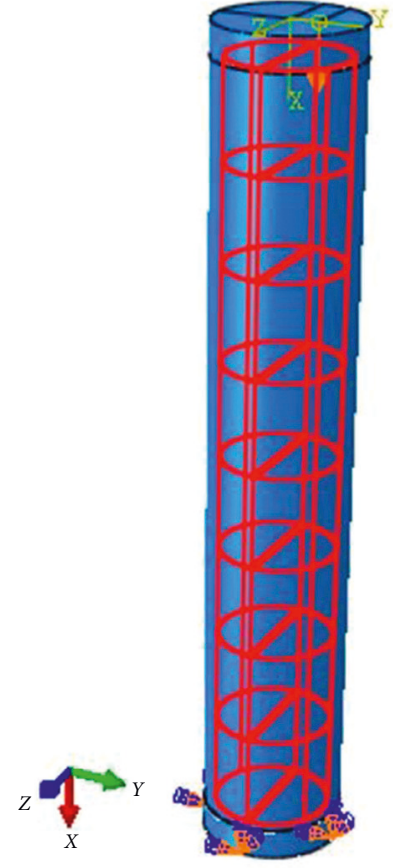

(c)

Figure 25: Cross-sectional shapes and geometry used to study load-deflection response of columns: (a) rectangular column; (b) square column; (c) circular column.

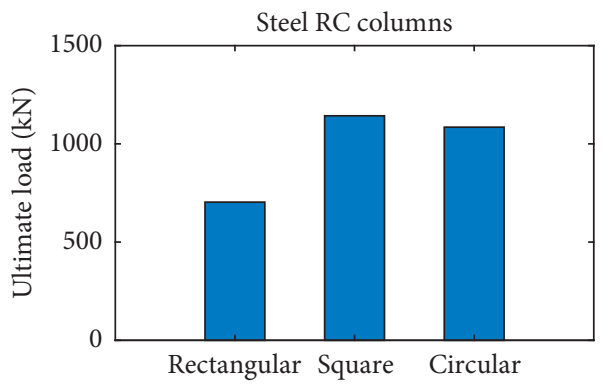

(a)

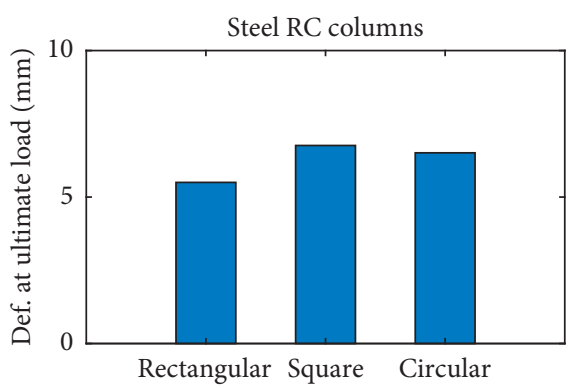

(c)

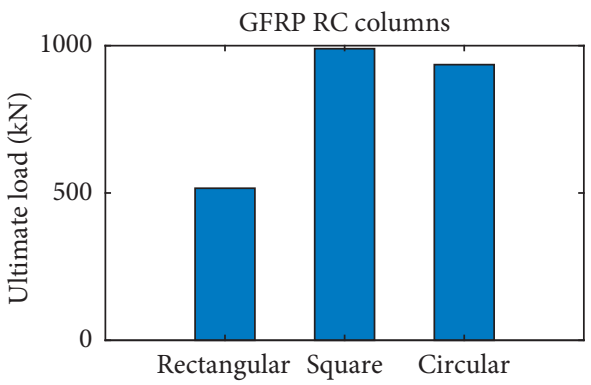

(b)

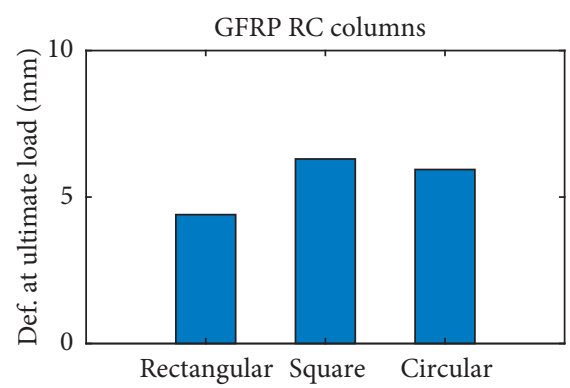

(d)

FIGURE 26: Cross-sectional shape effect on ultimate load and deflection at the ultimate load of steel and GFRP RC columns.

Therefore, it is concluded that, having the same crosssectional area with the same reinforcement ratios, the square column shows significant ultimate capacity for both steel- and GFRP-reinforced concrete members. Moreover, the manufacturing of circular GFRP ties is more complex, and they are inappropriate to be used in composite sections such as I-shaped and T-shaped sections.

\section{FEA Cracking Patterns}

According to concrete damaged plasticity (CDP) model, the cracking of concrete starts due to positive maximum principal plastic strain (PE). The direction of cracks in reinforced concrete is taken to be normal to maximum positive principal $\mathrm{PE}$, and therefore, the crack patterns are 
visualized through max. principal PE [34]. For the presentation of cracking patterns, tensile principal stress can be used in ABAQUS, but the plastic principal strains give better visualization of cracks. Figure 27 shows the maximum cracking patterns of steel and GFRP RC columns obtained from FEA simulations in ABAQUS Standard. In all concentric columns, the significant cracks occurred in upper half portion with the rupture of ligatures and concrete core crushing, while in eccentric columns, the tension cracks on the tension side were generated in lower half near the fixed support of columns. The FEA cracking patterns were found to be in good correspondence with experimental cracks. The rigid steel plates tied on top and bottom surfaces of columns were without cracks.

\section{Ultimate Strength and Empirical Equations}

The theoretical ultimate axial capacity of a short RC column is equal to the summation of the ultimate strength of the concrete material and yielding strength of longitudinal steel bars. In this article, the longitudinal reinforcement was taken the same as in the experimental and FEA work for concentric columns. The concrete cover (cc) was also taken the same as that was in experimental and FEA work, i.e., $40 \mathrm{~mm}$ for steel and $20 \mathrm{~mm}$ for GFRP RC columns. The gross cross-sectional area of GFRP RC columns is more due to less concrete cover (cc). According to the ACI code, the nominal strength $\left(P_{\mathrm{o}}\right)$ for an axially loaded steel-reinforced short column is given by the following equation:

$$
P_{\mathrm{o}}=0.85 f_{\mathrm{c}}^{\prime}\left(A_{\mathrm{g}}-A_{\mathrm{st}}\right)+A_{\mathrm{st}} f_{\mathrm{y}},
$$

where 0.85 is the reduction factor given in ACI 318-11 defined as the ratio of in-place strength to cylinder strength of concrete, $f_{\mathrm{c}}^{\prime}$ is the compressive strength of concrete, $A_{\mathrm{g}}$ is the gross cross-sectional area of concrete, $A_{\mathrm{st}}$ is the area of longitudinal steel, and $f_{\mathrm{y}}$ is the yield strength of longitudinal steel. ACI 318-11 ignores the participation of GFRP bars in axial load-carrying capacity of columns. The ACI 318-11 equation of axial capacity of GFRP RC columns using a reduction factor of 0.85 is shown as follows:

$$
P_{\mathrm{o}}=0.85 f_{\mathrm{c}}^{\prime}\left(A_{\mathrm{g}}-A_{\mathrm{F}}\right) \text {, }
$$

where $A_{\mathrm{F}}$ is the cross-sectional area of the longitudinal GFRP bars. Currently, Canadian Standard Association (CAN/CSA S806-12) allows the use of GFRP bars as main reinforcement in concentrically loaded columns only, neglecting their participation in axial capacity. The recommendation of CSA S806-12 is presented in the following equation:

$$
P_{\mathrm{o}}=\alpha_{1} f_{\mathrm{c}}^{\prime}\left(A_{\mathrm{g}}-A_{\mathrm{F}}\right) \text {, }
$$

where $\alpha_{1}=0.85-0.0015 f_{\mathrm{c}}^{\prime} \geq 0.67$. Afifi et al. [44] presented the following equation by considering the contribution of GFRP bars with a reduction factor $\alpha_{\mathrm{g}}$ :

$$
P_{\mathrm{o}}=0.85 f_{\mathrm{c}}^{\prime}\left(A_{\mathrm{g}}-A_{\mathrm{F}}\right)+\alpha_{\mathrm{g}} f_{\mathrm{fu}} A_{\mathrm{F}},
$$

where $A_{\mathrm{F}}$ is the cross-sectional area of main GFRP reinforcement, $f_{\mathrm{fu}}$ is the tensile strength of GFRP bars, and $\alpha_{\mathrm{g}}$ is the reduction factor for the compressive strength of GFRP bars. Kobayashi and Fujisaki [45] and Tobbi et al. [46] presented a value of 0.35 for this reduction factor.

The charts of Figure 28 show the comparison of experimental, FEA, and theoretical results of concentric steel and GFRP RC columns. It was noticed that the average percentage difference of theoretical peak loads of steel RC concentric columns given by equation (11) from experimental and numerical results was $7.87 \%$ and $8.45 \%$, respectively. The results of equations (12) and (13) underestimated the average axial capacity of GFRP RC columns by $20.94 \%$ and $22.38 \%$, respectively. However, the average percentage discrepancy of the results of equation (14) from experimental results was only $2.65 \%$. As compared with FEA results, equations (12)-(14) underestimated the peak loads of GFRP-reinforced columns on average by $22.38 \%, 25.30 \%$, and, $2.44 \%$, respectively. Therefore, it was concluded that the design equation provided by Afifi et al. [44] gave the acceptable results of GFRP RC specimens.

\section{Conclusions}

This research paper has endeavored to present the implementation of FEA using ABAQUS to predict the behavior of 13 steel- and GFRP-reinforced rectangular concentric and eccentric concrete columns subjected to axial loading. The constitutive selected numerical model was first calibrated and validated using test results of control specimen S45-150 and was then implemented for the analysis of remaining columns specimens and parametric analysis of two control samples. A theoretical comparative study for concentric steel and GFRP RC columns was also done. The concrete damaged plasticity model was used for the modelling of nonlinearity of reinforced concrete. In finite element modelling, the most challenging aspect is to model the materials accurately, especially the numerical modelling of concrete in concrete structures.

Based on the FEA results documented in the current study in comparison with the experimental results from Elchalakani and $\mathrm{Ma}$ [16], the following main conclusions were drawn:

(1) From FEA results, it was noted that the average ultimate capacity of GFRP-reinforced rectangular concrete columns was $96.14 \%$ of the average ultimate capacity of their steel-reinforced counterparts. The percentage discrepancy of the average capacity of experimental and FEA results was only $3.86 \%$. Therefore, due to less contribution of GFRP bars in the axial capacity of columns as compared with steel bars, it is recommended to use the GFRP bars in compression members where the involvement of reinforcement is less in axial loadcarrying capacity.

(2) There is an impact of variation of viscosity parameter, dilation angle, and mesh size on the FEA results. The peak load of the control specimen increases up to $16 \%$ when the viscosity parameter increases from 0.0018 to 0.0068 . Moreover, the peak load increases 
PE, max. principal

$$
\text { (avg: 75\%) }
$$

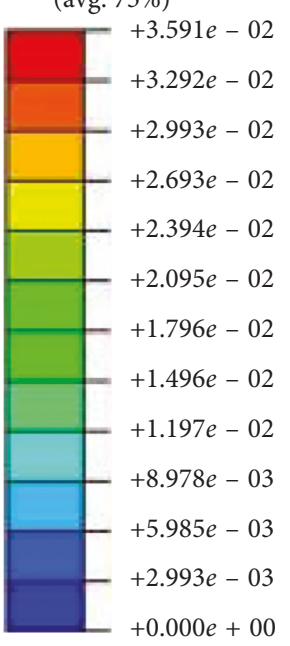

(a)

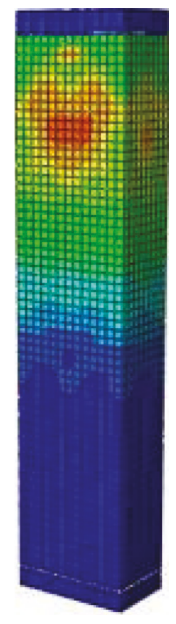

(b)

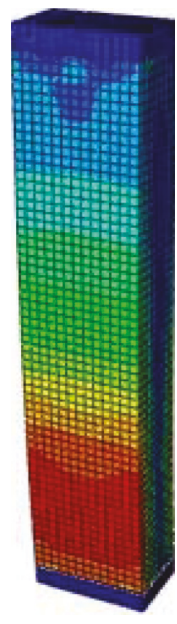

(c)

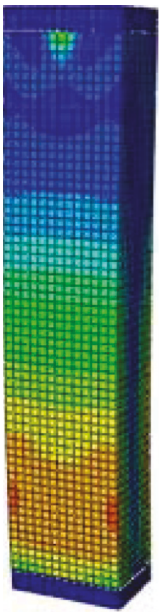

(d)

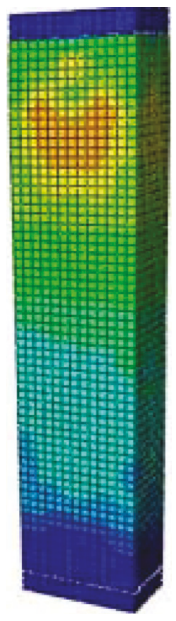

(e)

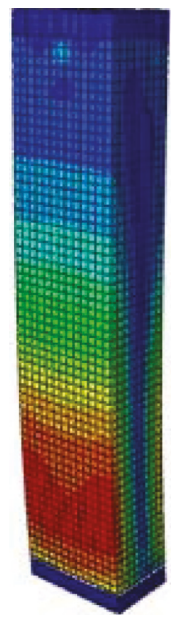

(f)

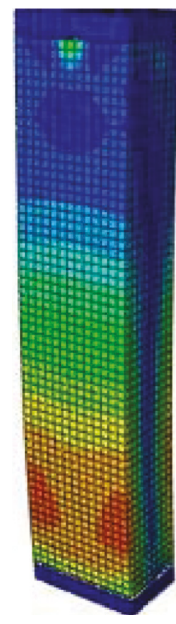

(g)

PE, max. principal (avg: 75\%)

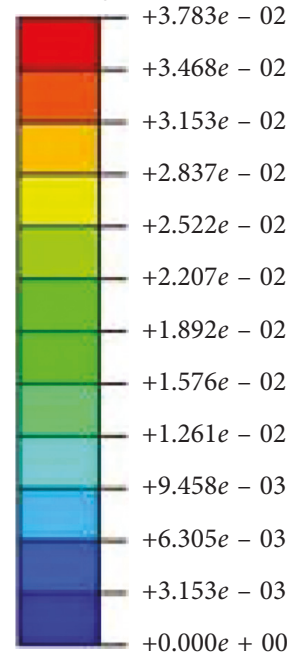

(h)

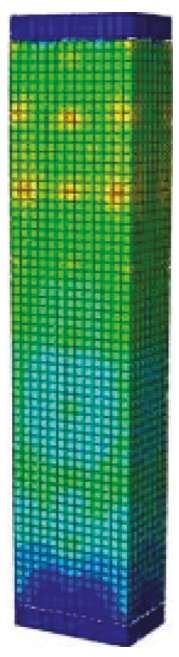

(i)

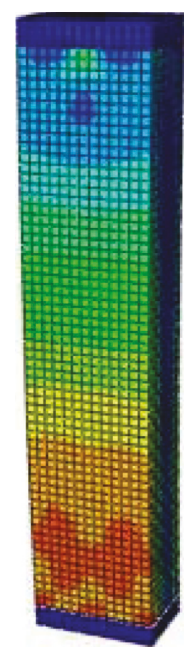

(j)

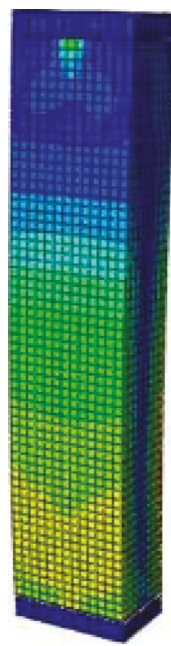

(k)

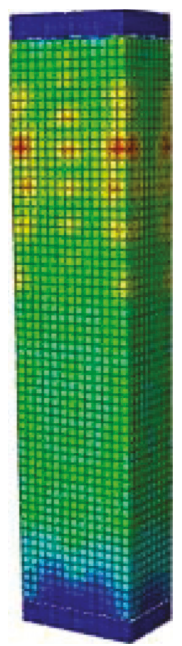

(1)

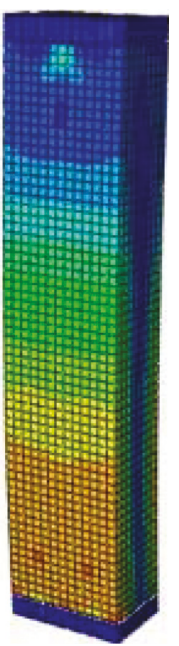

(m)

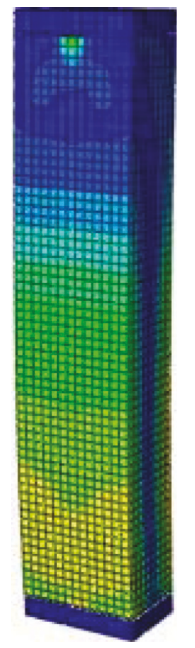

(n)

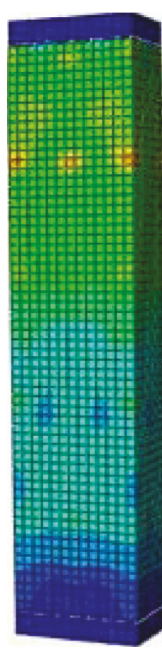

(o)

FIGURE 27: Max. +ve principal plastic strains of (a) SC-150 and (h) GC-150 and crack patterns for columns (b) SC-150, (c) S45-150, (d) S25150, (e) SC-75, (f) S35-75, (g) S25-75, (i) GC-150, (j) G45-150, (k) G25-150, (l) GC-75, (m) G35-75 (n) G25-75, and (o) GC-25.

up to $13 \%$ when mesh size decreases from $60 \mathrm{~mm}$ to $15 \mathrm{~mm}$. The effect of the dilation angle was only $4.75 \%$ when it increases from $30^{\circ}$ to $45^{\circ}$. The effect of the element types on load-deflection behavior was negligible. Therefore, the viscosity parameter and the mesh size appear to be critical for achieving the accurate results.

(3) Even small eccentricities caused by the construction errors and the geometrical imperfections of construction materials in GFRP-reinforced columns are of the great importance because they can cause a significant reduction in ultimate axial capacity of columns. In the presented FEA simulations, approximately a $39.74 \%$ reduction of the axial capacity of GFRP columns occurred for $25 \mathrm{~mm} \mathrm{ec-}$ centricity and $60.62 \%$ reduction occurred for $45 \mathrm{~mm}$ eccentricity when compared with an identical concentric column.

(4) The FEA results obtained from ABAQUS in terms of load-deflection curves were found to be consistent with the experimental results. The average discrepancies were $3.86 \%$ and $15.20 \%$ for steel-reinforced columns and $3.78 \%$ and $18.54 \%$ for GFRP-reinforced columns for loads and deflections, respectively. The material models used for numerical simulations produced slight overestimations for concentric columns. The premature failure of some eccentric columns occurred due to the opening of stirrups which caused the discrepancies. So, in future, it is endorsed to use the stirrups with lapped distance in ABAQUS simulations to avoid the premature failure of specimens. However, the FEA results show the capability of the selected numerical 


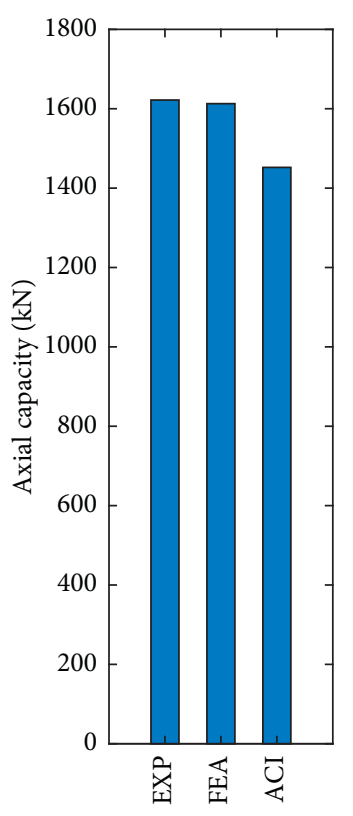

(a)

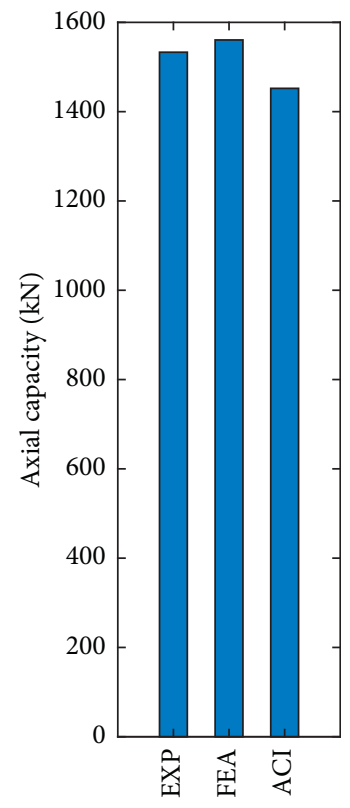

(b)

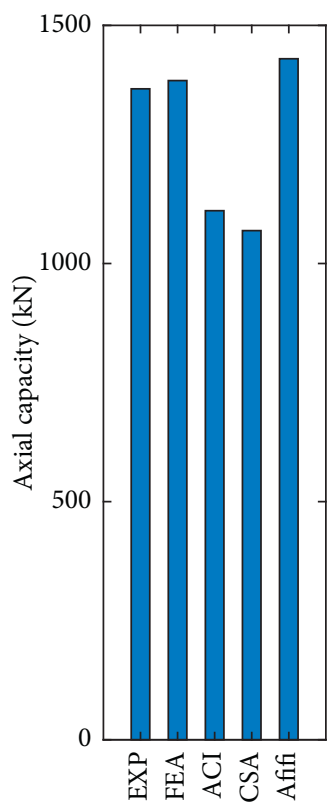

(c)

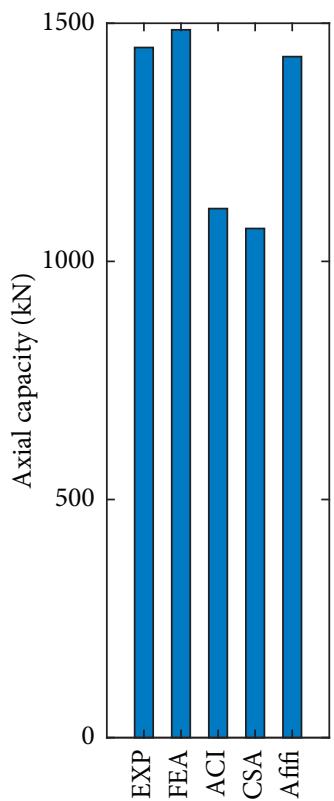

(d)

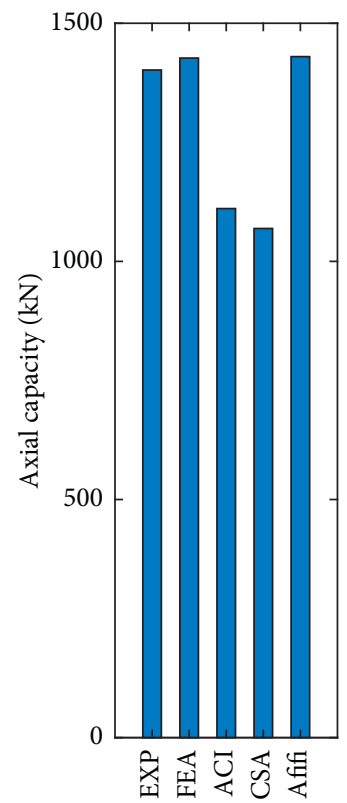

(e)

FIGURE 28: Comparison of ultimate axial capacity of concentric columns obtained from experimental, FE analysis, and theoretical results: (a) SC-150; (b) SC-75; (c) GC-150; (d) GC-75; (e) GC-250.

model for the prediction of load-deformation behavior of steel- and GFRP-reinforced columns.

(5) The numerical parametric study of one steelreinforced control specimen and one GFRPreinforced control specimen showed that the ultimate capacity of columns increases with the increase of compressive strength of concrete, with the increase of longitudinal reinforcement ratio and with the decrease of concrete cover. Furthermore, the square-shaped column was found to be the most efficient. The numerical parametric study results also confirmed the lower efficiency of GFRP bars in columns.

(6) The cracking patterns were also studied in current research showing the crushing of concrete in columns. The cracking pattern can be visualized through tensile principal stresses and maximum positive principal plastic strains, but the latter gives a better representation of cracking patterns. A good agreement was achieved for FEA cracking patterns in comparison with experimental cracks. As an assessment tool, the importance of FEA software 
ABAQUS is that the parametric studies of structural members can be done which are not possible by experimental investigations.

(7) The average percentage discrepancy of FEA results of steel RC concentric columns from empirical results was $8.45 \%$ and that of GFRP RC concentric columns was $2.44 \%$ using the design equation provided by $\mathrm{MZ}$ Afifi et al. Therefore, it is concluded that the presented FE model agreed well with experimental as well as theoretical results and can be utilized as a powerful and efficient numerical tool for the future studies on columns.

\section{Data Availability}

The data used to support the findings of this study are available from the corresponding author upon request.

\section{Conflicts of Interest}

The authors declare that they have no conflicts of interest.

\section{References}

[1] G. B. Maranan, A. C. Manalo, B. Benmokrane, W. Karunasena, and P. Mendis, "Behavior of concentrically loaded geopolymer-concrete circular columns reinforced longitudinally and transversely with GFRP bars," Engineering Structures, vol. 117, pp. 422-436, 2016.

[2] A. De Luca, F. Matta, and A. Nanni, "Behavior of full-scale glass fiber-reinforced polymer reinforced concrete columns under axial load," ACI Structural Journal, vol. 107, no. 5, p. $589,2010$.

[3] H. Tobbi, A. S. Farghaly, and B. Benmokrane, "Behavior of concentrically loaded fiber-reinforced polymer reinforced concrete columns with varying reinforcement types and ratios," ACI Structural Journal, vol. 111, no. 2, 2014.

[4] H. M. Mohamed, M. Z. Afifi, and B. Benmokrane, "Performance evaluation of concrete columns reinforced longitudinally with FRP bars and confined with FRP hoops and spirals under axial load," Journal of Bridge Engineering, vol. 19, no. 7, article 04014020, 2014.

[5] W. Prachasaree, S. Piriyakootorn, A. Sangsrijun, and S. Limkatanyu, "Behavior and performance of GFRP reinforced concrete columns with various types of stirrups," International Journal of Polymer Science, vol. 2015, Article ID 237231, 9 pages, 2015.

[6] S. Rizkalla, T. Hassan, and N. Hassan, "Design recommendations for the use of FRP for reinforcement and strengthening of concrete structures," Progress in Structural Engineering and Materials, vol. 5, no. 1, pp. 16-28, 2003.

[7] B. Benmokrane, E. El-Salakawy, A. El-Ragaby, and S. ElGamal, "Performance evaluation of innovative concrete bridge deck slabs reinforced with fibre-reinforced-polymer bars," Canadian Journal of Civil Engineering, vol. 34, no. 3, pp. 298-310, 2007.

[8] L. C. Bank, Composites for Construction: Structural Design with FRP Materials, John Wiley \& Sons, Hoboken, NJ, USA, 2006.

[9] T. T. Nguyen, T. M. Chan, and J. T. Mottram, "Influence of boundary conditions and geometric imperfections on lateral- torsional buckling resistance of a pultruded FRP I-beam by FEA," Composite Structures, vol. 100, pp. 233-242, 2013.

[10] W.-r. Yang, X.-j. He, and L. Dai, "Damage behaviour of concrete beams reinforced with GFRP bars," Composite Structures, vol. 161, pp. 173-186, 2017.

[11] A. M. Amiri, A. Olfati, S. Najjar, P. Beiranvand, and M. H. Naseri Fard, "The effect of fly ash on flexural capacity concrete beams," Advances in Science and Technology Research Journal, vol. 10, no. 30, pp. 89-95, 2016.

[12] M. A. Najafgholipour, S. M. Dehghan, A. Dooshabi, and A. Niroomandi, "Finite element analysis of reinforced concrete beam-column connections with governing joint shear failure mode," Latin American Journal of Solids and Structures, vol. 14, no. 7, pp. 1200-1225, 2017.

[13] S. H. Alsayed, Y. A. AI.Salloum, T. H. Almusallam, and M. A. Amjad, Concrete Columns Reinforced by Glass Fiber Reinforced Polymer Rods, American Concrete Institute, Farmington Hills, MI, USA, 1999.

[14] F. Nunes, M. Correia, J. R. Correia, N. Silvestre, and A. Moreira, "Experimental and numerical study on the structural behavior of eccentrically loaded GFRP columns," Thin-Walled Structures, vol. 72, pp. 175-187, 2013.

[15] G. Turvey and Y. Zhang, "A computational and experimental analysis of the buckling, postbuckling and initial failure of pultruded GRP columns," Computers \& Structures, vol. 84, no. 22-23, pp. 1527-1537, 2006.

[16] M. Elchalakani and G. Ma, "Tests of glass fibre reinforced polymer rectangular concrete columns subjected to concentric and eccentric axial loading," Engineering Structures, vol. 151, pp. 93-104, 2017.

[17] A. Mirmiran, K. Zagers, and W. Yuan, "Nonlinear finite element modeling of concrete confined by fiber composites," Finite Elements in Analysis and Design, vol. 35, no. 1, pp. 79-96, 2000.

[18] T. C. Rousakis, A. I. Karabinis, P. D. Kiousis, and R. Tepfers, "Analytical modelling of plastic behaviour of uniformly FRP confined concrete members," Composites Part B: Engineering, vol. 39, no. 7-8, pp. 1104-1113, 2008.

[19] A. I. Karabinis, T. C. Rousakis, and G. E. Manolitsi, "3D finiteelement analysis of substandard RC columns strengthened by fiber-reinforced polymer sheets," Journal of Composites for Construction, vol. 12, no. 5, pp. 531-540, 2008.

[20] B. Piscesa, M. M. Attard, and A. K. Samani, "Threedimensional finite element analysis of circular reinforced concrete column confined with FRP using plasticity model," Procedia Engineering, vol. 171, pp. 847-856, 2017.

[21] B. Alfarah, F. López-Almansa, and S. Oller, "New methodology for calculating damage variables evolution in Plastic Damage Model for RC structures," Engineering Structures, vol. 132, pp. 70-86, 2017.

[22] O. Youssf, M. A. ElGawady, J. E. Mills, and X. Ma, "Finite element modelling and dilation of FRP-confined concrete columns," Engineering Structures, vol. 79, pp. 70-85, 2014.

[23] W. X. M. Liu and Z. Chen, "Parameters calibration and verification of concrete damage plasticity model of Abaqus," Industrial Construction, vol. 44, pp. 167-213, 2014.

[24] Dassault Systems Simulia Corporation, ABAQUS Analysis User's Manual 6.10-EF, Dassault Systems Simulia Corporation, Providence, RI, USA, 2010.

[25] V. K. Papanikolaou and A. J. Kappos, "Confinement-sensitive plasticity constitutive model for concrete in triaxial compression," International Journal of Solids and Structures, vol. 44, no. 21, pp. 7021-7048, 2007. 
[26] P. Kmiecik and M. Kamiński, "Modelling of reinforced concrete structures and composite structures with concrete strength degradation taken into consideration," Archives of Civil and Mechanical Engineering, vol. 11, no. 3, pp. 623-636, 2011.

[27] S. Majewski, The Mechanics of Structural Concrete in Terms of Elasto-Plasticity, Publishing House of Silesian University of Technology, Gliwice, Poland, 2003.

[28] C. E. De Normalisation, Eurocode 2: Design of Concrete Structures-Part 1-1: General Rules and Rules for Buildings, European Committee for Standardisation, Brussels, Belgium, 2004.

[29] P. Desayi and S. Krishnan, "Equation for the stress-strain curve of concrete," ACI Journal Proceedings, vol. 61, no. 3, 1964.

[30] J. B. Mander, M. J. N. Priestley, and R. Park, "Theoretical stress-strain model for confined concrete," Journal of Structural Engineering, vol. 114, no. 8, pp. 1804-1826, 1988.

[31] R. Nayal and H. A. Rasheed, "Tension stiffening model for concrete beams reinforced with steel and FRP bars," Journal of Materials in Civil Engineering, vol. 18, no. 6, pp. 831-841, 2006.

[32] B. L. Wahalathantri, D. P. Thambiratnam, T. H. T. Chan, and S. Fawzia, "A material model for flexural crack simulation in reinforced concrete elements using ABAQUS," in Proceedings of the First International Conference on Engineering, Designing and Developing the Built Environment for Sustainable Wellbeing, Queensland University of Technology, Brisbane, Australia, April 2011.

[33] P. Wong, F. Vecchio, and H. Trommels, "VecTor2 and FormWorks user's manual," Technical Report, Department of Civil Engineering, University of Toronto, Toronto, Canada, 2002.

[34] A. S. Genikomsou and M. A. Polak, "Finite element analysis of punching shear of concrete slabs using damaged plasticity model in ABAQUS," Engineering Structures, vol. 98, pp. 3848, 2015 .

[35] M. Elchalakani, A. Karrech, M. Dong, M. S. Mohamed Ali, and B. Yang, "Experiments and finite element analysis of GFRP reinforced geopolymer concrete rectangular columns subjected to concentric and eccentric axial loading," Structures, vol. 14, pp. 273-289, 2018.

[36] A. M. A. Ibrahim, M. F. M. Fahmy, and Z. Wu, "3D finite element modeling of bond-controlled behavior of steel and basalt FRP-reinforced concrete square bridge columns under lateral loading," Composite Structures, vol. 143, pp. 33-52, 2016.

[37] D. I. Kachlakev and T. Miller, Finite Element Modeling of Reinforced Concrete Structures Strengthened with FRP Laminates, Oregon Department of Transportation Research Group \& Federal Highway Administration, Washington, DC, USA, 2001.

[38] J. Lee and G. L. Fenves, "A plastic-damage concrete model for earthquake analysis of dams," Earthquake Engineering \& Structural Dynamics, vol. 27, no. 9, pp. 937-956, 1998.

[39] J. Lee and G. L. Fenves, "Plastic-damage model for cyclic loading of concrete structures," Journal of Engineering $\mathrm{Me}$ chanics, vol. 124, no. 8, pp. 892-900, 1998.

[40] G. Z. Voyiadjis and Z. N. Taqieddin, "Elastic plastic and damage model for concrete materials: Part I-theoretical formulation," International Journal of Structural Changes in Solids-Mechanics and Applications, vol. 1, no. 1, pp. 31-59, 2009.
[41] J. Y. Wu, J. Li, and R. Faria, "An energy release rate-based plastic-damage model for concrete," International Journal of Solids and Structures, vol. 43, no. 3-4, pp. 583-612, 2006.

[42] K. T. Nguyen, N. Ahn, T. A. Le, and K. Lee, "Theoretical and experimental study on mechanical properties and flexural strength of fly ash-geopolymer concrete," Construction and Building Materials, vol. 106, pp. 65-77, 2016.

[43] N. F. Hany, E. G. Hantouche, and M. H. Harajli, "Finite element modeling of FRP-confined concrete using modified concrete damaged plasticity," Engineering Structures, vol. 125, pp. 1-14, 2016.

[44] M. Z. Afifi, H. M. Mohamed, and B. Benmokrane, "Axial capacity of circular concrete columns reinforced with GFRP bars and spirals," Journal of Composites for Construction, vol. 18, no. 1, article 04013017, 2013.

[45] K. Kobayashi and T. Fujisaki, "32 compressive behavior of FRP reinforcement in non-prestressed concrete members," in Proceedings of the Second International RILEM Symposium on Non-Metallic (FRP) Reinforcement for Concrete Structures, CRC Press, Ghent, Belgium, August 1995.

[46] H. Tobbi, A. S. Farghaly, and B. Benmokrane, "Concrete columns reinforced longitudinally and transversally with glass fiber-reinforced polymer bars," ACI Structural Journal, vol. 109, no. 4, 2012. 


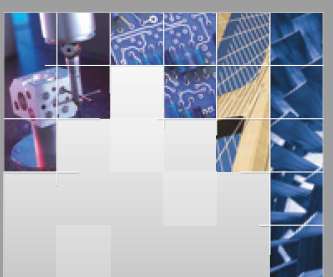

\section{Enfincering}
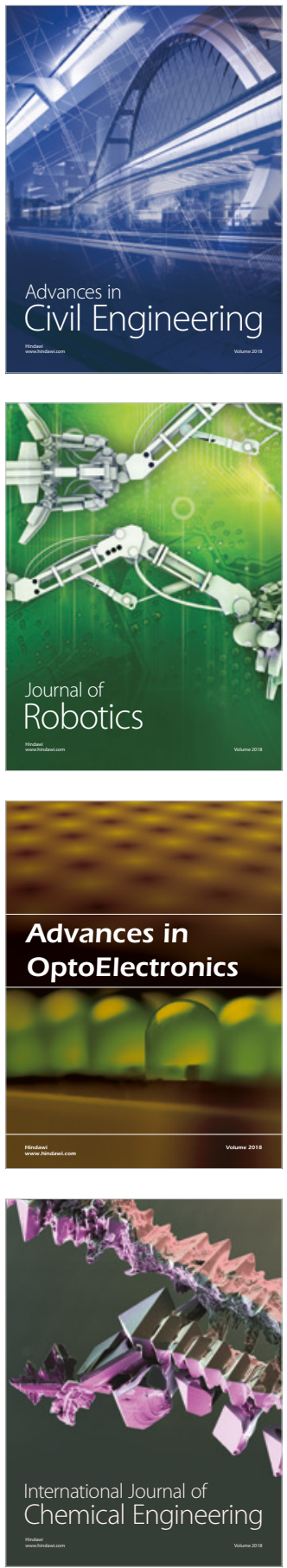

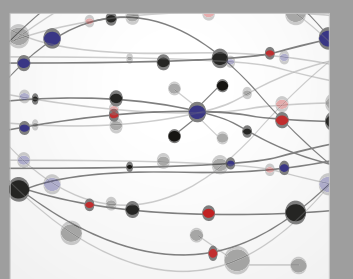

\section{Rotating \\ Machinery}

The Scientific World Journal

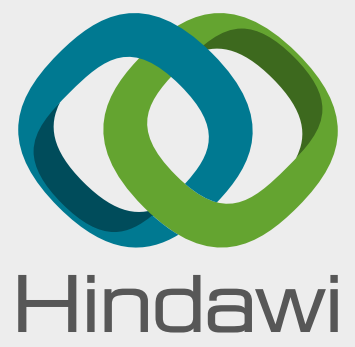

Submit your manuscripts at

www.hindawi.com
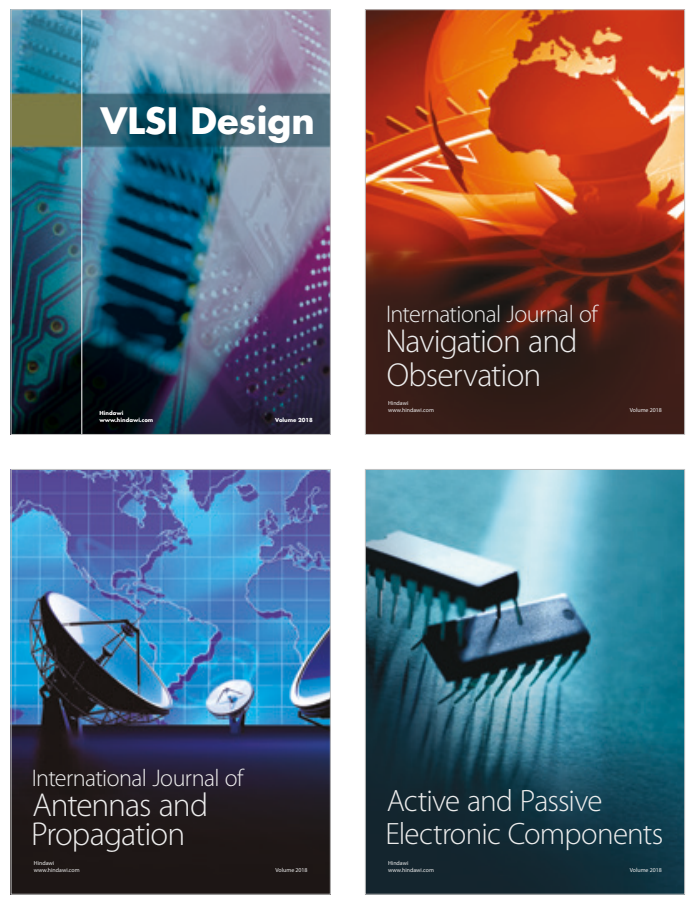
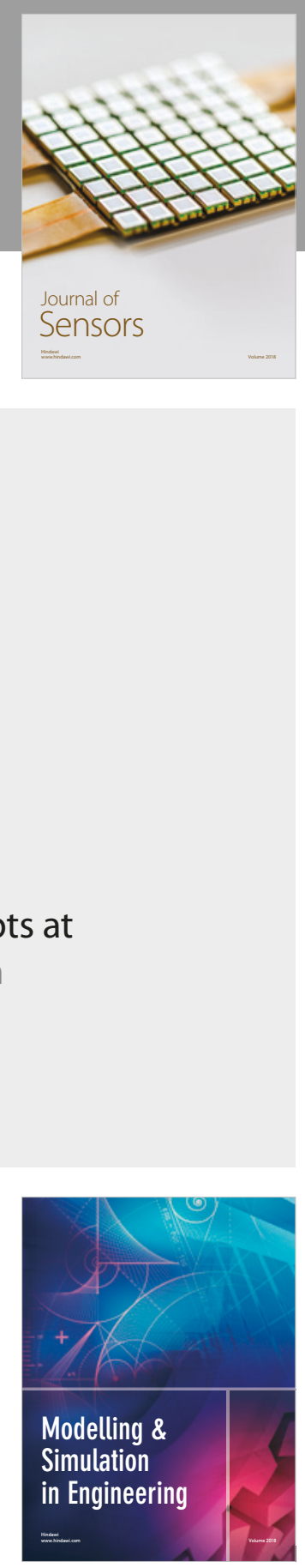

\section{Advances \\ Multimedia}
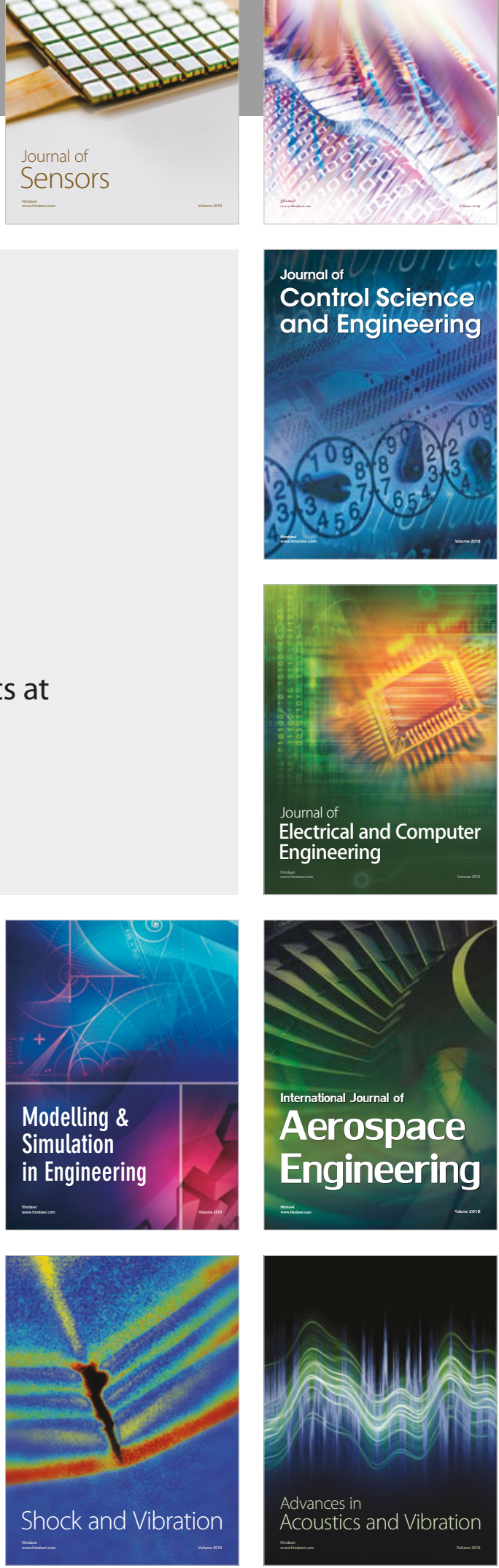